\title{
Surface-based Ku- and Ka-band polarimetric radar for sea ice studies
}

\author{
Julienne Stroeve ${ }^{1,2,3}$, Vishnu Nandan ${ }^{1}$, Rosemary Willatt $^{2}$, Rasmus Tonboe ${ }^{4}$, Stefan Hendricks ${ }^{5}$, Robert Ricker ${ }^{5}$, \\ James Mead $^{6}$, Robbie Mallett ${ }^{2}$, Marcus Huntemann ${ }^{5,7}$, Polona Itkin ${ }^{8}$, Martin Schneebeli ${ }^{9}$, Daniela Krampe ${ }^{5}$, \\ Gunnar Spreen $^{7}$, Jeremy Wilkinson ${ }^{10}$, Ilkka Matero ${ }^{5}$, Mario Hoppmann ${ }^{5}$, and Michel Tsamados ${ }^{2}$ \\ ${ }^{1}$ Centre for Earth Observation Science, University of Manitoba, 535 Wallace Building, Winnipeg, MB, R3T 2N2, Canada \\ ${ }^{2}$ Earth Sciences Department, University College London, Gower Street, London, WC1E 6BT, UK \\ ${ }^{3}$ National Snow and Ice Data Center, University of Colorado, 1540 30th Street, Boulder, CO 80302, USA \\ ${ }^{4}$ Danish Meteorological Institute, Lyngbyvej 100, 2100 Copenhagen, Denmark \\ ${ }^{5}$ Alfred Wegener Institute, Am Handelshafen 12, 27570 Bremerhaven, Germany \\ ${ }^{6}$ ProSensing, 107 Sunderland Road, Amherst, MA 01002-1357, USA \\ ${ }^{7}$ Institute of Environmental Physics, University of Bremen, Otto-Hahn-Allee 1, 28359 Bremen, Germany \\ ${ }^{8}$ Department of Physics and Technology, UiT The Arctic University of Norway, Troms $\varnothing, 9019$, Norway \\ ${ }^{9}$ WSL Institute for Snow and Avalanche Research SLF, Fluelastrasse 11, 7260 Davos Dorf, Switzerland \\ ${ }^{10}$ British Antarctic Survey, High Cross, Madingley Road, Cambridge, CB3 0ET, UK
}

Correspondence: Julienne Stroeve (julienne.stroeve@umanitoba.ca)

Received: 15 June 2020 - Discussion started: 3 August 2020

Revised: 14 October 2020 - Accepted: 20 October 2020 - Published: 4 December 2020

\begin{abstract}
To improve our understanding of how snow properties influence sea ice thickness retrievals from presently operational and upcoming satellite radar altimeter missions, as well as to investigate the potential for combining dual frequencies to simultaneously map snow depth and sea ice thickness, a new, surface-based, fully polarimetric $\mathrm{Ku}-$ and $\mathrm{Ka}$-band radar (KuKa radar) was built and deployed during the 2019-2020 year-long MOSAiC international Arctic drift expedition. This instrument, built to operate both as an altimeter (stare mode) and as a scatterometer (scan mode), provided the first in situ $\mathrm{Ku}$ - and $\mathrm{Ka}$-band dual-frequency radar observations from autumn freeze-up through midwinter and covering newly formed ice in leads and first-year and secondyear ice floes. Data gathered in the altimeter mode will be used to investigate the potential for estimating snow depth as the difference between dominant radar scattering horizons in the Ka- and $\mathrm{Ku}$-band data. In the scatterometer mode, the $\mathrm{Ku}$ - and Ka-band radars operated under a wide range of azimuth and incidence angles, continuously assessing changes in the polarimetric radar backscatter and derived polarimetric parameters, as snow properties varied under varying atmospheric conditions. These observations allow for character-
\end{abstract}

izing radar backscatter responses to changes in atmospheric and surface geophysical conditions. In this paper, we describe the KuKa radar, illustrate examples of its data and demonstrate their potential for these investigations.

\section{Introduction}

Sea ice is an important indicator of climate change, playing a fundamental role in the Arctic energy and freshwater balance. Furthermore, because of complex physical and biogeochemical interactions and feedbacks, sea ice is also a key component of the marine ecosystem. Over the last several decades of continuous observations from multifrequency satellite passive microwave imagers, there has been a nearly $50 \%$ decline in Arctic sea ice extent at the time of the annual summer minimum (Stroeve and Notz, 2018; Stroeve et al., 2012; Parkinson and Cavalieri, 2002; Cavalieri et al., 1999). This loss of sea ice area has been accompanied by a transition from an Arctic Ocean dominated by older and thicker multiyear ice (MYI) to one dominated by younger and thinner first-year ice (FYI; Maslanik et al., 2007, 2011). While 
younger ice tends to be thinner and more dynamic, much less is known about how thickness and volume are changing. Accurate ice thickness monitoring is essential for heat and momentum budgets, ocean properties, and the timing of sea ice algae and phytoplankton blooms (Bluhm et al., 2017; Mundy et al., 2014).

Early techniques to map sea ice thickness relied primarily on in situ drilling, ice mass balance buoys, and upwardlooking sonar on submarines and moorings, providing limited spatial and temporal coverage, and have been logistically difficult. More recently, electromagnetic systems, including radar and laser altimeters flown on aircraft and satellites, have expanded these measurements to cover the pan-Arctic region. However, sea ice thickness is not directly measured by laser or radar altimeters. Instead these types of sensors measure the ice or snow freeboard, which when combined with assumptions about the amount of snow on the ice; radar penetration of the surface; and the snow, ice and water densities, can be converted into total sea ice thickness assuming hydrostatic equilibrium (Laxon et al., 2003; Laxon et al., 2013; Wingham et al., 2006; Kurtz et al., 2009).

Current satellite-based radar altimeters, such as the European Space Agency (ESA) Ku-band CryoSat-2 (CS2), in operation since April 2010, and the Ka-band SARAL-AltiKa, launched in February 2013 as part of a joint mission by the Centre National d'Études Spatiales (CNES) and the Indian Space Research Organisation (ISRO), provide the possibility of mapping pan-Arctic (up to $81.5^{\circ} \mathrm{N}$ for AltiKa) sea ice thickness (Tilling et al., 2018; Hendricks et al., 2016; Kurtz and Harbeck, 2017; Armitage and Ridout, 2015). It may also be possible to combine Ku- and Ka-bands to simultaneously retrieve both ice thickness and snow depth during winter (Lawrence et al., 2018; Guerreiro et al., 2016). Other studies have additionally suggested the feasibility of combining CS2 with snow freeboard observations from laser altimetry (e.g., ICESat-2) to map pan-Arctic snow depth and ice thickness during the cold season (Kwok and Markus, 2018; Kwok et al., 2020).

However, several key uncertainties limit the accuracy of the radar-based freeboard retrieval, which then propagate into the freeboard-to-thickness conversion. One important uncertainty pertains to inconsistent knowledge on how far the radar signal penetrates into the overlying snow cover (Nandan et al., 2020; Willatt et al., 2011; Drinkwater, 1995). The general assumption is that the radar return primarily originates from the snow-sea ice interface at the Ku-band (CS2) and from the air-snow interface at the Ka-band (AltiKa). While this may hold true for cold, dry snow in a laboratory (Beaven et al., 1995), scientific evidence from observations and modeling suggests this assumption may be invalid even for a cold, homogeneous snowpack (Nandan et al., 2020; Willatt et al., 2011; Tonboe et al., 2010). Modeling experiments also reveal that for every millimeter of snow water equivalent (SWE), the effective scattering surface is raised by $2 \mathrm{~mm}$ relative to the freeboard (Tonboe, 2017). A further complication is that radar backscattering is sensitive to the presence of liquid water within the snowpack. This means that determining the sea ice freeboard using radar altimeters during the transition phase into Arctic summer is not possible (Beaven et al., 1995; Landy et al., 2019). The transition from an MYI- to FYI-dominated Arctic has additionally resulted in a more saline snowpack, which in turn impacts the snow brine volume, thereby affecting snow dielectric permittivity. This vertically shifts the location of the Ku-band radar scattering horizon by several centimeters above the snow-sea ice interface (Nandan et al., 2020; Nandan et al., 2017b; Tonboe et al., 2006). As a result, field campaigns have revealed that the dominant radar scattering actually occurs within the snowpack or at the snow surface rather than at the snow-ice interface (Willatt et al., 2011; Giles et al., 2007). Another complication is that surface roughness and subfootprint preferential sampling may also impact the location of the main radar scattering horizon (Tonboe et al., 2010; Landy et al., 2019). All these processes combined result in significant uncertainty as to accurately detecting the location of the dominant Ku-band scattering horizon and in turn influence the accuracy of sea ice thickness retrievals from satellites. This would also create biases in snow depth retrievals obtained from combining dual-frequency radar observations or from combining radar and laser altimeter observations, as recently done in Kwok et al. (2020).

Other sources of error in radar altimeter sea ice thickness retrievals include assumptions about ice, snow and water densities used in the conversion of freeboard to ice thickness; inhomogeneity of snow and ice within the radar footprint; and snow depth. Lack of snow depth and SWE knowledge provides the largest uncertainty (Giles et al., 2007). Yet snow depth is not routinely retrieved from satellite measurements despite efforts to use multifrequency passive microwave brightness temperatures to map snow depth over FYI (Markus et al., 2011) and also over MYI (Rostosky et al., 2018). Instead, climatological values are often used, based on data collected several decades ago on MYI (Warren et al., 1999; Shalina and Sandven, 2018). These snow depths are arguably no longer valid for the first-year ice regime which now dominates the Arctic Ocean (70\% FYI today vs. $30 \%$ in 1980s). To compensate, radar altimeter processing groups have halved the snow climatology over FYI (Tilling et al., 2018; Hendricks et al., 2016; Kurtz and Farrell, 2011), yet climatology does not reflect actual snow conditions on either FYI or MYI for any particular year and also does not reflect the spatial variability at the resolution of a radar altimeter. The change in ice type, combined with large delays in autumn freeze-up and earlier melt onset (Stroeve and Notz, 2018), has resulted in a much thinner snowpack compared to that in the 1980s (Stroeve et al., 2020a; Webster et al., 2014). The use of an unrepresentative snow climatology can result in substantial biases in total sea ice thickness if the snow depth departs strongly from this climatology. Moreover, snow depth is also needed for the radar propagation de- 
lay in the freeboard retrieval and for estimating snow mass in the freeboard-to-thickness conversion. If snow depth is unknown and climatology is used instead, error contributions are stacked and amplified when freeboard is converted to ice thickness. Therefore, the potential to combine $\mathrm{Ku}-$ and $\mathrm{Ka}-$ bands to map snow depth, radar penetration and ice thickness at radar footprint resolution is an attractive alternative and forms one of the deltas of a possible follow-on mission to CS2, such as ESA's Copernicus candidate mission CRISTAL (Kern et al., 2020).

Besides altimeters, active radar remote sensing has proven its capability to effectively characterize changes in snow and sea ice geophysical and thermodynamic property conditions, at multiple microwave frequencies (Barber and Nghiem, 1999; Drinkwater, 1989; Gill et al., 2015; Komarov et al., 2015; Nandan et al., 2016; Nandan et al., 2017a). Snow and its associated geophysical and thermodynamic properties play a central role in the radar signal propagation and scattering within the snow-covered sea ice media (Barber and Nghiem 1999; Nandan et al., 2017a; Barber et al., 1998; Yackel and Barber, 2007; Nandan et al., 2020). This in turn impacts the accuracy of satellite-derived estimates of critical sea ice state variables, including sea ice thickness; snow depth; SWE; and timings of melt, freeze and pond onset.

At $\mathrm{Ku}$ - and Ka-bands, currently operational and upcoming synthetic-aperture radar (SAR) missions operate over a wide range of polarizations, spatial and temporal resolutions, and coverage areas. Due to the presence of possible spatial heterogeneity of snow and sea ice types present within a satellite-resolution grid cell, the sensors add significant uncertainty to direct retrievals of snow and sea ice state variables. In addition, radar signals acquired from these sensors may be temporally decorrelated, owing to dynamic temporal variability in snow and sea ice geophysical and thermodynamic properties. To avoid this uncertainty, highspatial-resolution and high-temporal-resolution in situ measurements of radar backscatter from snow-covered sea ice are necessary, quasi-coincident to unambiguous in situ measurements of snow and sea ice geophysical and thermodynamic properties (Nandan et al., 2016; Geldsetzer et al., 2007). Although a wide range of research has utilized dual- and multifrequency microwave approaches to characterize the thermodynamic and geophysical state of snow-covered sea ice, using surface-based and airborne multifrequency, multipolarization measurements (Nandan et al., 2016; Nandan et al., 2017a; Beaven et al., 1995; Onstott et al., 1979; Livingstone et al., 1987; Lytle et al., 1993), no studies have been conducted using coincident dual-frequency $\mathrm{Ku}$ - and $\mathrm{Ka}$-band radar signatures of snow-covered sea ice to investigate the potential of effectively characterizing changes in snow and sea ice geophysical and thermodynamic properties with variations in atmospheric forcing.

From a radar altimetry standpoint, there are differences in scattering mechanisms from surface- and satellite-based systems. From a satellite-based system, the radar backscatter is dominated by surface scattering, while for a surface-based radar system, the backscatter coefficient is much lower, because the surface-based system is not affected by the high coherent scattering from large facets (large relative to the wavelength) within the Fresnel reflection zone (Fetterer et al., 1992). In addition, observations from ground-based radar systems can target homogenous surfaces and thus directly interpret the coherent backscatter contribution of the various surface types which are often mixed in satellite observations and require backscatter decomposition. Therefore, it is important to study the $\mathrm{Ku}$ - and $\mathrm{Ka}$-band radar propagation and behavior in snow-covered sea ice, using surface-based systems, and how they can be used for understanding scattering from satellite systems.

To improve our understanding of snowpack variability in the dominant scattering horizon relevant to satellite radar altimetry studies, as well as of backscatter variability for scatterometer systems, a Ku- and Ka-band dual-frequency, fully polarimetric radar (KuKa radar) was built and deployed during the year-long Multidisciplinary drifting Observatory for the Study of Arctic Climate (MOSAiC) international Arctic drift expedition (https://mosaic-expedition.org/ expedition/, last access: 2 December 2020). The KuKa radar provides a unique opportunity to obtain a benchmark dataset, involving coincident field, airborne and satellite data, from which we can better characterize how the physical properties of the snowpack (above different ice types) influence the $\mathrm{Ka}-$ and Ku-band backscatter and penetration. Importantly, for the first time we are able to evaluate the seasonal evolution of the snowpack over FYI and MYI. MOSAiC additionally provides the opportunity for year-round observations of snow depth and its associated geophysical and thermodynamic properties, which will allow for rigorous assessment of the validity of climatological assumptions typically employed in thickness retrievals from radar altimetry as well as provide data for validation of snow depth products. These activities are essential if we are to improve sea ice thickness retrievals and uncertainty estimation from radar altimetry over the many ice and snow conditions found in the Arctic and the Antarctic.

This paper describes the KuKa radar and its early deployment during MOSAiC, including some initial demonstration of fully polarimetric data (altimeter and scatterometer modes) collected over different ice types from mid-October 2019 through the end of January 2020. This preliminary study fits well within the context of conducting a larger seasonal analysis of coincident $\mathrm{Ka}$ - and $\mathrm{Ku}$-band radar signatures and their evolution over snow-covered sea ice from autumn freeze-up through winter to melt onset and back to freeze-up, once all data collected during the MOSAiC campaign become available. 


\section{The Ku- and Ka-band dual-frequency system}

Given the importance of snow depth for sea ice thickness retrievals from satellite radar altimetry, several efforts are underway to improve upon the use of a snow climatology. One approach is to combine freeboards from two satellite radar altimeters of different frequencies, such as AltiKa and CS2, to estimate snow depth (Lawrence et al., 2018; Guerreiro et al., 2016). Early studies comparing freeboards from these two satellites showed AltiKa retrieved different elevations over sea ice than CS2 did (Armitage and Ridout, 2015), paving the way forward for combining these satellites to map snow depth. However, freeboard differences showed significant spatial variability and suggested Ka-band signals are sensitive to surface and volume scattering contributions from the uppermost snow layers and Ku-band signals are sensitive to snow layers that are saline and complexly layered (via rain-on-snow and melt-refreeze events). These complexities in snow properties largely impact the $\mathrm{Ka}$ - and $\mathrm{Ku}$-band radar penetration depth. Penetration depths at the $\mathrm{Ka}$ - and $\mathrm{Ku}$-band evaluated against NASA's Operation IceBridge (OIB) freeboards found mean penetration factors (defined as the dominant scattering horizon in relation to the snow and ice surfaces) of 0.45 for AltiKa and 0.96 for CS2 (Armitage and Ridout, 2015). A key limitation of this approach however is that, it is based on OIB data that cover a limited region of the Arctic Ocean and are only available during springtime. OIB snow depths also have much smaller footprints than the large footprints of CS2 and AltiKa. Further, this approach assumes that the OIB-derived snow depths are correct.

Biases from sampling differences, potential temporal decorrelation between different satellites and processing techniques also play a role. With regards to combining AltiKa and CS2, the larger AltiKa pulse-limited footprint compared to the CS2 beam sharpening leads to different sensitivities to surface roughness due to the different footprint sizes illuminating a different instantaneous surface. This approach is further complicated by the fact that the satellite radar pulses have traveled through an unknown amount of snow, slowing the speed of the radar pulse, leading to radar freeboard retrievals that differ from actual sea ice freeboards. Other sources of biases in the radar processing chain include (i) uncertainty in the return pulse retracking, (ii) off-nadir reflections from leads or "snagging", (iii) footprint broadening for rougher topography, and (iv) surface type mixing in the satellite footprints.

\section{Methods}

\subsection{The KuKa radar}

Sea ice thickness is not directly measured by laser or radar altimeters. Instead, sensors such as CS2 retrack the return waveform based on scattering assumptions, and from that the ice freeboard $\left(f_{\mathrm{i}}\right)$ can be derived. This can be converted to ice thickness ( $h_{\text {ice }}$ ) assuming hydrostatic equilibrium together with information on snow depth $\left(h_{\text {snow }}\right)$, snow density $\left(\rho_{\text {snow }}\right)$, ice density $\left(\rho_{\text {ice }}\right)$ and water density $\left(\rho_{\text {water }}\right)$ following Eq. (1):

$h_{\text {ice }}=\frac{\rho_{\text {snow }} h_{\text {snow }}+\rho_{\text {water }} f_{\mathrm{i}}}{\rho_{\text {water }}-\rho_{\text {ice }}}$.

Snow and ice density are not spatially homogeneous: sea ice density is related to the age of the ice (FYI vs. MYI), while snow density can cover a large spectrum of values depending on weather conditions and heat fluxes. How far the radar signal penetrates into the snowpack determines $f_{\mathrm{i}}$, which depends on the dielectric permittivity $(\varepsilon)$ of the snowpack, or the ability of the snowpack to transmit the electric field (Ulaby et al., 1986), and the scattering in the snowpack from the snow microstructure and scattering at the air-snow, snow-sea ice and internal snow layers. The permittivity can be written as $\varepsilon=\varepsilon^{\prime}+i \varepsilon^{\prime \prime}$, where $\varepsilon^{\prime}$ is the real part of the permittivity and $\varepsilon^{\prime \prime}$ is the imaginary part, and depends on $\rho_{\text {snow }}$ and the frequency of the radiation penetrating through the snowpack: the higher the $\varepsilon^{\prime \prime}$, the more the field strength is reduced (absorption). Dry snow is a mixture of ice and air, and therefore its complex permittivity $\varepsilon$ depends on the dielectric properties of ice, snow microstructure and snow density (Ulaby et al., 1986). In general, dry-snow permittivity scales linearly with $\rho_{\text {snow }}$, such that increasing $\rho_{\text {snow }}$ increases $\varepsilon^{\prime}$ (Ulaby et al., 1986). A further complication is that radar backscattering is sensitive to the presence of liquid water and brine within the snowpack (Tonboe et al., 2006; Hallikainen, 1977), such that $\varepsilon^{\prime}$ for water inclusions is 40 times larger than for dry snow, decreasing the depth to which the radar will penetrate. In other words, small amounts of liquid water lead to a lower penetration depth (Winebrenner et al., 1998). Negative freeboards can additionally lead to snow flooding creating a slush layer and wicking up of moisture. This can all lead to the presence of moisture in the snowpack even in winter months when the air temperature would indicate that the snow is cold and dry, and hence, the dominant scattering surface in the Ku-band would be assumed to be the snow-ice interface (Beaven et al., 1995). The processes listed here determine the shape of the radar altimeter waveform, and the subsequent impact on the freeboard depends on the retracker algorithm applied on the altimeter waveform, to determine the location of the main radar backscatter horizon (e.g., Ricker et al., 2014).

When developing an in situ radar system to study radar penetration into the snowpack, it is important to consider how the snow dielectric permittivity and surface and volume scattering contributions to the total backscatter change temporally (both diurnally and seasonally), as new snow accumulates and is modified by wind redistribution, temperature gradients and salinity evolution over newly formed sea ice. Surface scattering dominates from dielectric interfaces such as the air-snow interface, internal snow layers and the snow- 
sea ice interface, while volume scattering dominates from the snow microstructure or from inclusions within the ice (Ulaby et al., 1986). For snow and ice surfaces, surface scattering dominates (i.e., from the snow surface, from the ice surface and from internal snow layering). Because snow is a dense media, scattering from individual snow grains is affected by the grains' neighbors, and the volume scattering is not simply the noncoherent sum of all scatterers but must include multiple scattering effects. With surface-based radar systems, it is important to understand what kind of scattering mechanisms are to be expected from the snow and sea ice media.

To resolve the scattering properties of snow from the surface and subsurface layers, the new KuKa radar designed by ProSensing Inc. was configured to operate both as an altimeter and as a scatterometer. Built for polar conditions, the $\mathrm{KuKa}$ radar transmits at $\mathrm{Ku}-(12-$ $18 \mathrm{GHz})$ and at Ka- $(30-40 \mathrm{GHz})$ bands using a very low power transmitter, making it suitable for short ranges (typically less than $30 \mathrm{~m}$ ). Both $\mathrm{Ku}-$ and $\mathrm{Ka}$-band radio frequency (RF) units are dual-polarization, solid-state FMCW (frequency-modulated continuous-wave) radars using linear FM (frequency-modulated) modulation. Each system employs a linear FM synthesizer with variable bandwidth for two modes, fine and coarse range resolution. The system is configured to always operate in fine mode, with a bandwidth of 6 and $10 \mathrm{GHz}$ at $\mathrm{Ku}-$ and Ka-bands, respectively, but any segment of the $12-18$ or $30-40 \mathrm{GHz}$ bandwidth can be processed to achieve any desired range resolution above $2.5 \mathrm{~cm}$ (Ku-band) or $1.5 \mathrm{~cm}$ (Ka-band). Coarse-rangeresolution processing is centered on the satellite frequencies of CS2 and AltiKa (e.g., 13.575 and $35.7 \mathrm{GHz}$, respectively), with an operating bandwidth of $500 \mathrm{MHz}$, yielding a $30 \mathrm{~cm}$ range resolution. Polarization isolation of the antennas is greater than $30 \mathrm{~dB}$. An internal calibration loop, consisting of an attenuator and $4.2 \mathrm{~m}$ long delay line (electrical delay $=20 \mathrm{~ns}$ ), is used to monitor system stability. These calibration loop data are used in the data processing software to compensate for any power drift as a result of temperature changes. During the polar winter, air temperatures regularly drop to -30 to $-40^{\circ} \mathrm{C}$, while cyclones entering the central Arctic can result in air temperatures approaching $0{ }^{\circ} \mathrm{C}$ during midwinter (Graham et al., 2017). The RF units are insulated and heated to stabilize the interior temperature under such cold conditions. Given that this instrument was designed for polar conditions, it is not intended to be operated at temperatures above $15^{\circ} \mathrm{C}$. Operating parameters for each $\mathrm{RF}$ unit are summarized in Table 1.

The antennas of each radar are dual-polarized scalar horns with a beamwidth of $16.5^{\circ}$ at the Ku-band and $11.9^{\circ}$ at the Ka-band, with a center-to-center spacing of $13.36 \mathrm{~cm}(\mathrm{Ku}-$ band) and $7.65 \mathrm{~cm}$ (Ka-band). Thus, they are not scanning exactly at the same surface because of slightly different footprints. However, the different footprint sizes of each band are to some extent averaged out by the spatial and temporal averaging (discussed in Sect. 2.3). Further, they do not take data at the same rate. At the Ku-band, a new block of data is gathered every $0.5 \mathrm{~s}$, while at the Ka-band a new block of data is gathered every $0.33 \mathrm{~s}$. Also, the two instruments' GPS data are independent of each other, so any random drift in the latitude or longitude can have a small effect on the estimated position. Further, data acquisition is not precisely time-aligned between the two instruments: start times vary by $\sim 0.5 \mathrm{~s}$. The radar employs a fast linear FM synthesizer and pulse-to-pulse polarization switching, which allows the system to measure the complex scattering matrix of a target in less than $10 \mathrm{~ms}$. This allows the scattering matrix to be measured well within the decorrelation distance (approximately half the antenna diameter) when towing the radar along the transect path at $1-2 \mathrm{~m} / \mathrm{s}$.

During the MOSAiC field campaign, the radar was operated both in a nadir "stare" (or altimeter) mode and in a "scan" (or scatterometer) mode when attached to a pedestal that scans over a programmed range of azimuth and incidence angles $(\theta$; see Fig. 1). In this configuration, the radar and positioner were powered by $240 \mathrm{~V} \mathrm{AC} 50 \mathrm{~Hz}$ power to the input of the uninterruptible power supply (UPS) mounted on the pedestal. For the altimeter mode, the RF units were unmounted from the positioner and attached to a ridge frame attached to a transect sled. Two $12 \mathrm{~V}$ DC batteries were used to power the RF units during the stare mode.

In the stare-transect mode, the radar measures the backscatter at nadir $\left(\theta=0^{\circ}\right)$ as a function of time. In stare mode, a new file is generated and stored every $5 \mathrm{~min}$. The radar data were processed in segments based on the lateral travel distance of the sledge where the instrument was placed. Given the radar antenna diameters $(0.15 \mathrm{~m}$ for $\mathrm{Ku}$ and $0.09 \mathrm{~m}$ for $\mathrm{Ka}$ ), the lateral distance traveled by the sledge needs to be 0.5 times the antenna diameters or 0.075 and $0.045 \mathrm{~m}$ for the $\mathrm{Ku}-$ and Ka-bands, respectively. The minimum velocity was set to $0.4 \mathrm{~m} / \mathrm{s}$ to avoid a drifting GPS location appearing as true motion.

In the scatterometer mode, both the $\mathrm{Ka}$ - and the $\mathrm{Ku}$ band scatterometer beams scan at the programmed $\theta$, moving across the azimuth within a prescribed azimuthal angular width. The system then moves up to the next $\theta$ at a set of increments (e.g., $5^{\circ}$ used for our measurements) and scans the next elevation line along the same azimuthal angular width. New files for both $\mathrm{Ku}-$ and Ka-bands are generated each time the positioner begins a scan. The footprint of the KuKa radar during one complete scan is a function of the $\mathrm{Ku}$ - and Ka-band antenna beamwidth and the system geometry, with the footprint increasing in area, as the incidence angle increases from the nadir to far range. At a $\sim 1.5 \mathrm{~m}$ (positioner + pedestal + sledge) height, the KuKa footprint is $\sim 15 \mathrm{~cm}$ at nadir and $\sim 90 \mathrm{~cm}$ (Ku-band) and $\sim 70 \mathrm{~cm}$ (Ka-band) at $50^{\circ}$. With $5^{\circ}$ increments in $\theta$ steps, there is an $\sim 60 \%$ (Kaband) to $70 \%$ (Ku-band) overlap within the adjacent incidence angle scans. The number of independent range gates at nadir is about 6 (Ku-band) and 10 (Ka-band), and at a $50^{\circ}$ incidence angle, the range gates are about 36 (Ku-band) 
Table 1. Summary of Ka- and Ku-band specifications.

\begin{tabular}{lll}
\hline & Ku-band & Ka-band \\
\hline Radar parameter & Value & Value \\
\hline RF output frequency & $12-18 \mathrm{GHz}$ & $30-40 \mathrm{GHz}$ \\
\hline $\begin{array}{l}\text { Transmit power (at the output of RF } \\
\text { unit bulkhead connector) }\end{array}$ & $10 \mathrm{dBm}$ & $6 \mathrm{dBm}$ \\
\hline Transmit bandwidth & $6 \mathrm{GHz}$ & $10 \mathrm{GHz}$ \\
\hline Range resolution & $2.5 \mathrm{~cm}$ & $1.5 \mathrm{~cm}$ \\
\hline Antenna 6 dB two-way beamwidth & $16.9^{\circ}$ at $13.575 \mathrm{GHz}$ & $11.9^{\circ}$ at $35 \mathrm{GHz}$ \\
\hline Cross-polarization isolation & $>30 \mathrm{~dB}$ & $>30 \mathrm{~dB}$ \\
\hline Transmit-receive polarization & $\mathrm{VV}, \mathrm{HH}, \mathrm{HV}, \mathrm{VH}$ & $\mathrm{VV}, \mathrm{HH}, \mathrm{HV}, \mathrm{VH}$ \\
\hline Chirp length & $1-99 \mathrm{~ms}(\mathrm{set}$ to $2 \mathrm{~ms}$ for normal operation) & $1-99 \mathrm{~ms}$ (set to $2 \mathrm{~ms}$ for normal operation) \\
\hline Digitizer & 14 bit resolution, $5 \mathrm{MS} / \mathrm{s}$ raw sample rate & 14 bit resolution, $5 \mathrm{MS} / \mathrm{s}$ raw sample rate \\
\hline Noise floor & $-70 \mathrm{~dB}(\mathrm{VV}, \mathrm{HH})$ & $-90 \mathrm{~dB}$ (VV, HH, HV, VH) \\
\hline
\end{tabular}

and 46 (Ka-band). The number of $\mathrm{Ka}$ - and $\mathrm{Ku}$-band independent samples was obtained by dividing the azimuthal angular width $\left(90^{\circ}\right)$ by half of the antenna beamwidth and multiplying it by the number of range gates falling within the scatterometer footprint. Based on the range gates, at nadir and at a $50^{\circ}$ incidence angle, the $\mathrm{KuKa}$ radar produces 162 (nadir) and $450\left(50^{\circ}\right)$ and 972 (nadir) and $2070\left(50^{\circ}\right)$ independent samples, for $\mathrm{Ku}$ - and $\mathrm{Ka}$-bands, respectively. A detailed description of range gate and independent samples calculation can be found in King et al. (2012) and Geldsetzer et al. (2007). No near-field correction is applied, since the antenna far-field distance is about $1 \mathrm{~m}$. An external calibration was separately carried out for calculating the radar cross section per unit area (NRCS) and polarimetric quantities, conducted at the remote sensing (RS) site on 16 January 2020, using a trihedral corner reflector positioned in the antenna's far field $(\sim 10 \mathrm{~m})$. In regard to long-term stability, the internal calibration loop tracks any gain variations, including in the cables to the antenna and the antenna ports on the switches. Periodic calibration checks were performed with the corner reflector. A detailed description of the polarimetric calibration procedure is provided in the Supplement, following Sarabandi et al. (1990) and adopted in Geldsetzer et al. (2007) and King et al. (2012).

Since snow consists of many small individual scatterers and scattering facets, with each scatterer having a scattering coefficient, the radar pulse volume consists of a large number of independent scattering amplitudes depending on the size of the antenna and the radar footprint; the size, roughness and slope of the scattering facets; and the size and shape of snow and ice scatterers, i.e., snow structure and air bubbles or brine pockets in the ice. Thus, any particular radar sample received by the RF unit consists of a complex sum of voltages received from all individual scatterer facets as well as from multiple interactions among these. Regardless of the distribution of the scattering coefficients, the fact that they are at different ranges from the antenna gives rise to a random-walk sum, which exhibits a bivariate Gaussian distribution in the complex voltage plane. The power associated with the bivariate Gaussian distribution has a Rayleigh distribution, with a large variance. Thus, to reduce the variance, the radar sweeps across several azimuthal angles or, in the case of the nadir view, across a specified distance. There is always a tradeoff between obtaining enough averaging to converge to the correct mean value for all of the polarimetric values measured by the radar for the enhanced range resolution and avoiding too much spatial averaging. For the nadir view, the minimum distance traveled to ensure statistically independent samples is half of the antenna diameter. An onboard GPS was used to track the radar location, and sample values were only included in the final average if the antenna had moved at least half a diameter from the previously included data samples.

The system can be operated remotely through the internet using the wide area network connection provided. Raw data are stored on the embedded computer for each RF unit. A web page allows the user to monitor system operation, configure the scanning of the radar, set up corner reflector calibration and manually move the positioner as well as manage and download the raw data files.

\subsection{KuKa radar setup and deployment}

The MOSAiC Central Observatory (CO) around the German research vessel (R/V) Polarstern was established on an oval- 


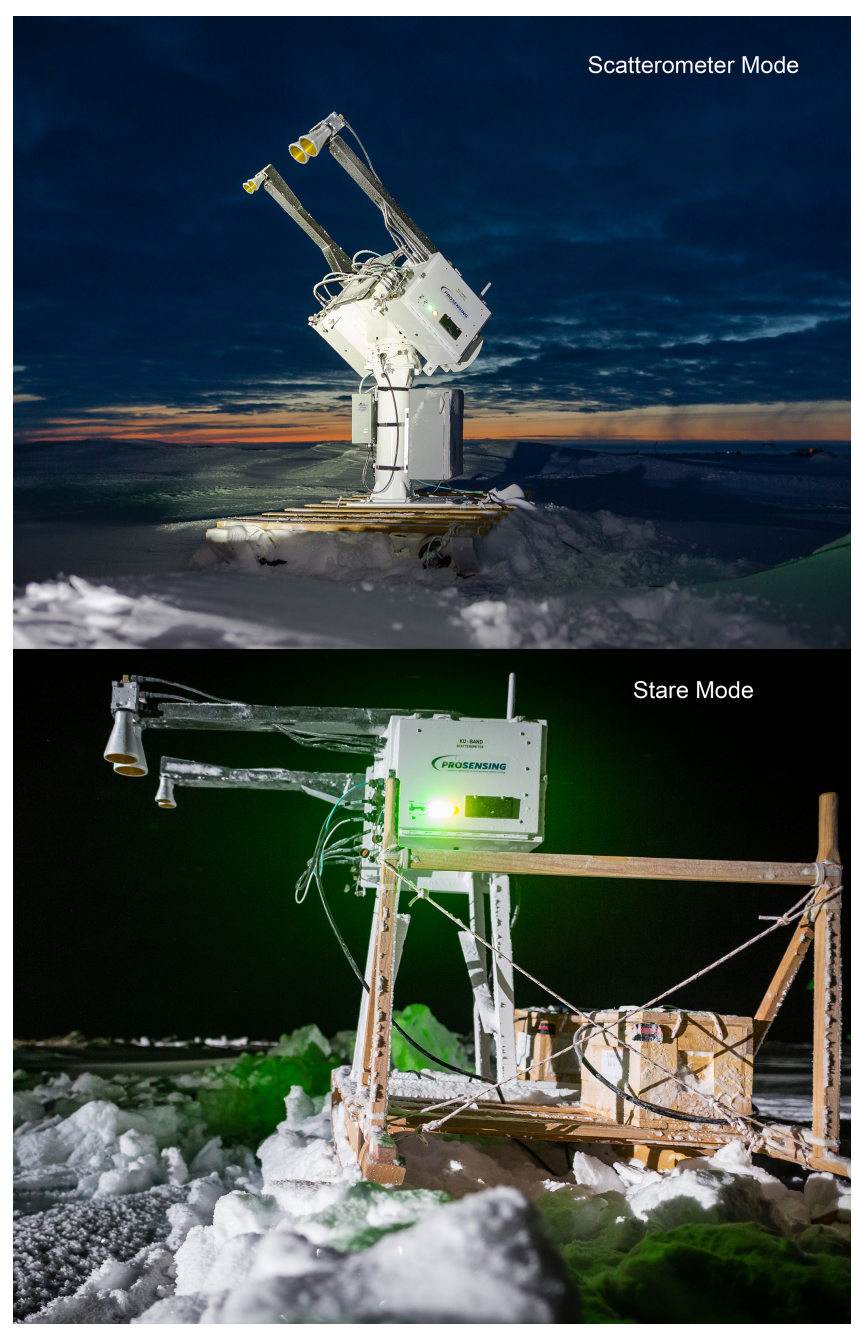

Figure 1. Configuration of KuKa radar in scatterometer scan (top) and altimeter stare (bottom) modes. Photo credit: Stefan Hendricks.

shaped ice floe of approximately $3.8 \mathrm{~km}$ by $2.8 \mathrm{~km}$, located north of the Laptev Sea $\left(85^{\circ} \mathrm{N}, 136^{\circ} \mathrm{E}\right)$. The floe was formed north of the New Siberian Islands, via a polynya event, at the beginning of December 2018 (Krumpen et al., 2020). This floe underwent extensive weathering and survived the 2019 summer melt, was heavily deformed, and consisted of predominantly remnant second-year ice (SYI). The ridged (or thick) part of the floe was called the "fortress", where all permanent installations were placed. At the beginning of the floe setup, the bottom of the ice was rotten, with only the top $30 \mathrm{~cm}$ solid. The melt pond fraction was greater than $50 \%$. The first deployment of the KuKa radar was on 18 October 2019 at the remote sensing (RS) site (Fig. 2), on a section of the ice that was approximately $80 \mathrm{~cm}$ thick. However, the ice pack was quite dynamic, and a large storm on 1618 November caused breakup of the CO, and all RS instruments were turned off and moved to a temporary safe location. On 26 November, the complete RS site was moved closer to MET City (atmospheric meteorological station), on a refrozen melt pond, a site also with about $80 \mathrm{~cm}$ thick ice, although overall the snow was slightly deeper. The instrument was redeployed on 29 November and operated until 12 December when several leads formed and all instruments were once again moved to thicker ice and turned off. The KuKa radar started measuring again on 21 December 2019 and continued until 31 January 2020, after which the radar was taken off the RS site to conduct maintenance. All three RS sites were chosen to scan snow-covered SYI, exhibiting similar snow and SYI properties. Characterization of the spatial and temporal evolution of Ku- and Ka-band radar penetration into the snow was achieved with two configurations of the radar: (1) near-hourly $(55 \mathrm{~min})$ scanning across $90^{\circ}$ azimuth and incidence angles between $0^{\circ}$ and $50^{\circ}$ at $5^{\circ}$ increments, at the RS site, and (2) repeated weekly transects of $1-8 \mathrm{~km}$ in length in nadir-stare mode.

Detailed snow and sea ice geophysical property observations were obtained as close as possible to the RS site, via weekly snow pits, biweekly snow depth measurements (around each RS instrument) and the collection of occasional ice cores. These observations included snow specific surface area (SSA), the scatter correlation length and density derived from a SnowMicroPen (SMP) force measurements (see Proksch et al., 2015), snow-air and snow-ice interface temperatures with a temperature probe, snow salinity with a salinometer, and SWE using a $50 \mathrm{~cm}$ metal ETH tube together with a spring scale. In the case of hard crusts that were too hard for the SMP to work, snow density was collected using a density cutter. In addition to these basic snow pit measurements, near-infrared (NIR) photography and micro-CT scanning were also conducted. On the one hand, the NIR camera allows for the determination of snow layers with different SSAs at a spatial resolution of about $1 \mathrm{~mm}$ (Matzl and Schneebeli, 2006). Micro-CT scanning on the other hand provides 3D details on snow microstructure using X-ray microtomography. A thermal infrared (TIR) camera (InfraTec VarioCam HDx head 625) was set up to spatially observe the surface temperature of the entire remote sensing footprint at regular $10 \mathrm{~min}$ intervals. The setup was supported by a visual surveillance camera taking pictures at $5 \mathrm{~min}$ intervals to resolve events, such as snow accumulation and the formation of snow dunes. During leg 2 of the MOSAiC expedition (i.e., 15 December 2019 through 22 February 2020), ice cores were collected near the RS instruments, cut into short cores at $3 \mathrm{~cm}$ intervals for the top $20 \mathrm{~cm}$ and at $5 \mathrm{~cm}$ intervals for the remaining core, melted to room temperature, and measured for layerwise salinity. During leg 1, sea ice thickness measurements made via drill holes ranged between 80 and $96 \mathrm{~cm}$. At the start of leg 2, ice thickness at the third established RS site was $92 \mathrm{~cm}$, increasing to $135 \mathrm{~cm}$ (29 January). Measurements of sea ice freeboards during leg 2 ranged between 7 and $10 \mathrm{~cm}$. Ice cores revealed overall low salinity $(<1 \mathrm{ppt})$, until the few centimeters above to the ice-water interface, where salinities increased between 6 and 8 ppt. The upper $20 \mathrm{~cm}$ of 


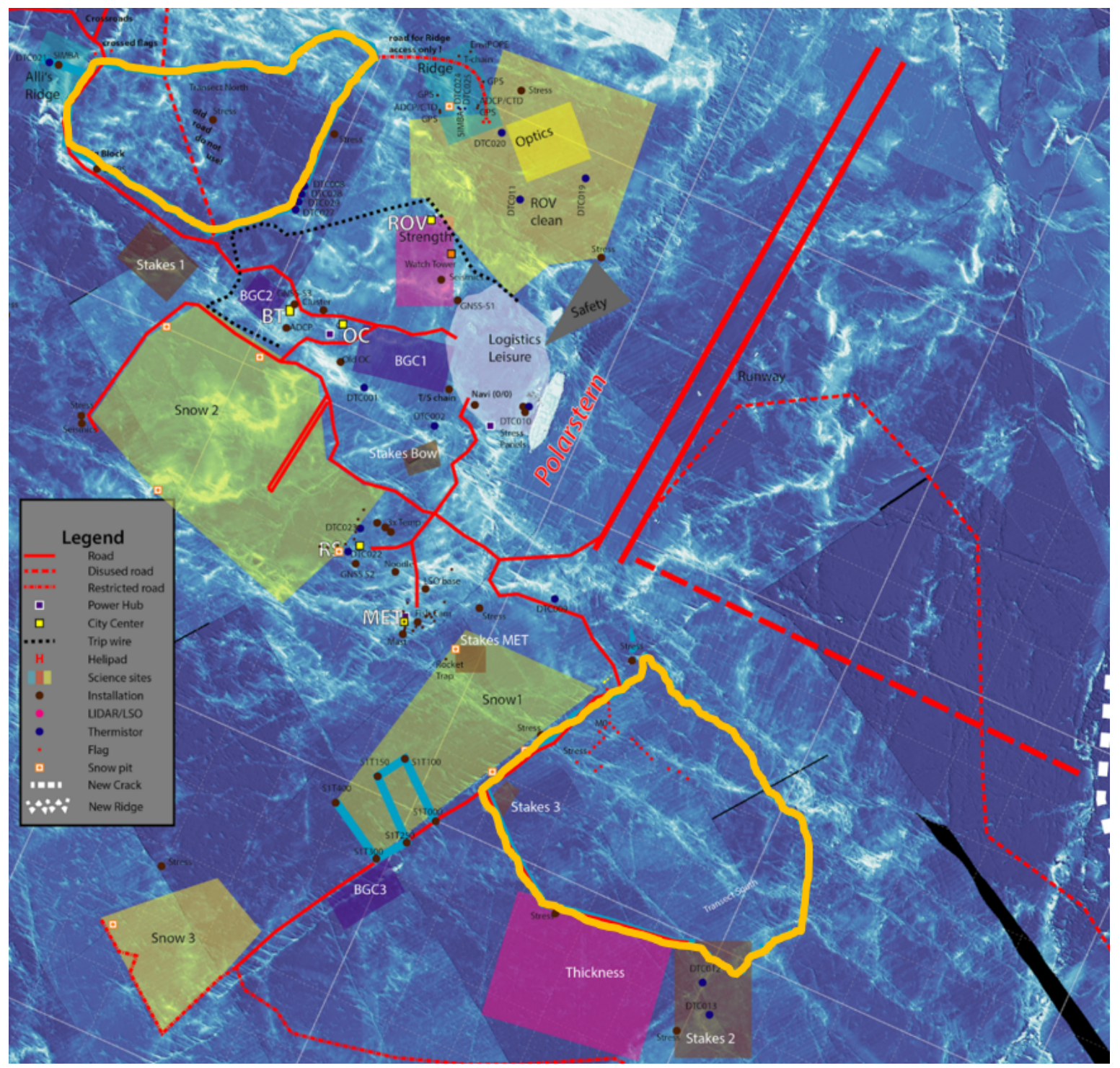

Figure 2. Annotated schematic of the Central Observatory $(\mathrm{CO})$ around R/V Polarstern. The schematic is overlaid on a postprocessed airborne laser scanner map, acquired on 21 February 2020. The remote sensing site is denoted by "RS". The northern (top left) and southern (bottom right) transects are outlined in bold orange.

the ice, which was comprised of refrozen melt ponds, was relatively consistent in its low salinity $(0-0.5 \mathrm{ppt})$. Finally, two digital thermistor strings (DTCs) were installed at the RS site and provided additional information on temperature profiles within the snow and ice (at a $2 \mathrm{~cm}$ vertical resolution), from which snow depth and sea ice thickness can be inferred.

For the stare-transect mode, nadir-view radar measurements were collected in parallel with snow depth from a Magnaprobe (rod of $1.2 \mathrm{~m}$ in length; Sturm and Holmgren, 2018) equipped with GPS and a ground-based broadband electromagnetic induction sensor for total ice thickness (Geophex GEM-2). The CO included both a northern and a southern transect loop (Fig. 2), with the northern loop rep- resenting thicker and rougher ice and the southern loop representing younger and thinner ice that had been formed in former melt ponds. Snow pit measurements were collected along a portion of the northern transect, at six select locations typically spaced $\sim 100 \mathrm{~m}$ apart. At each pit, SMP measurements provided SSA and snow density information (five measurements at each location), together with snow-air and snow-ice interface temperatures, snow salinity, and SWE.

While these data were routinely collected to support interpretation of the radar backscatter, snow on sea ice is spatially variable at a variety of scales as wind redistribution results in the formation of snow dunes and bedforms (Moon et al., 2019; Filhol and Sturm, 2015). Further, different ice types (i.e., FYI vs. MYI) have different temporal evolutions 


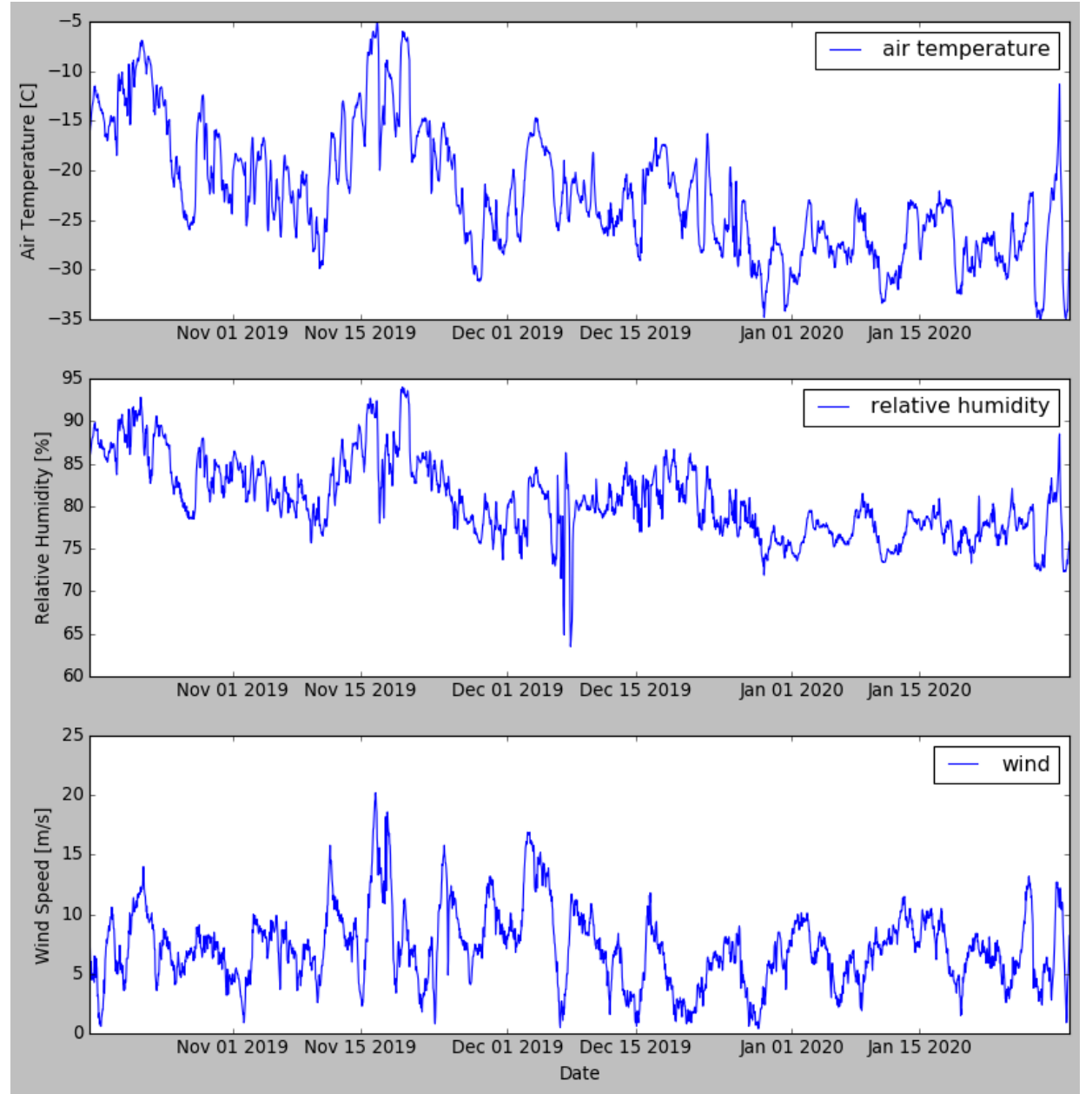

Figure 3. Summary of weather data during deployment of KuKa radar, measured from R/V Polarstern. Shown are the air temperature, relative humidity and the wind speed from 18 October 2019 to 31 January 2020 at $30 \mathrm{~m}$ height.

of snow depth. In recognition of the spatially and temporally varying snowpacks, other detailed snow pits were made over different ice conditions, including ridged ice, newly formed lead ice with snow accumulation, level FYI and MYI, and refrozen melt ponds. The key requirement was to adapt the snow sampling to these situations and conduct sampling after significant snowfall and/or snow redistribution. This was especially important for the transect data which sampled several snow and ice types not represented by the six snow pits. All these data collected in tandem with the KuKa radar will enable in-depth investigations of how snowpack variability influences the radar backscatter.

This paper focuses on showing examples of the data collected during the first $31 / 2$ months of operation (18 October 2019 through 31 January 2020 during MOSAiC legs 1 and 2), in both scan (scatterometer) and stare (altimeter) modes. In-depth analysis of how snowpack properties influence the dual-frequency radar returns will form follow-on papers. Nevertheless, we show here examples for different ice types and under different atmospheric conditions. Air tem- peratures between October and January fluctuated between -5 and $-35^{\circ} \mathrm{C}$ as measured on the ship (Fig. 3a), while the ice surface temperature measurements via the TIR camera and the DTC (Fig. 4) were usually colder than the ship temperatures. During this time, a total number of 18 transectstare mode operations of the KuKa were made. Table 3 summarizes the dates over which the transects were made, as well as other opportune sampling. We should note that during leg 1, only two short northern loop transects that covered the remote sensing section were sampled. In addition, one frost flower event was sampled over $10 \mathrm{~cm}$ thin ice. During leg 2 , the team made weekly transects starting 19 December 2019 until the KuKa radar was taken off the ice for maintenance. In addition, the team made two transects over FYI along the "runway" built on the port side of the ship and two lead transects spaced a day apart.

In the results section, we highlight results during a relatively warm and cold time period to see how air and snow surface temperature influences the $\mathrm{Ku}$ - and Ka-band polarimetric backscatter and derived polarimetric parameters at the 
Table 2. Summary of snow pit properties along northern transect. Values are given as averages, standard deviations, and min and max (in parentheses) from two to six snow pits. Results show considerable variability in snow water equivalent (SWE) and snow depth.

\begin{tabular}{|c|c|c|c|c|c|c|}
\hline Date & Mean snow wa & $\begin{array}{l}\text { equivalent } \\
\text { WE; mm) }\end{array}$ & $\begin{array}{r}\text { Mean snow depth } \\
(\mathrm{cm})\end{array}$ & & $\begin{array}{r}\text { Mean density } \\
\left(\mathrm{kg} / \mathrm{m}^{3}\right)\end{array}$ & $\begin{array}{r}\text { Mean bulk salinity } \\
(\mathrm{ppt})\end{array}$ \\
\hline 19 December 2019 & $50.75 \pm 38.07$ & $(19,105)$ & $19.0 \pm 12.99 \quad(9,38)$ & $256.5 \pm 39.46$ & $(211.1,300.0)$ & $0.1 \pm 0.05$ \\
\hline 26 December 2019 & $36.75 \pm 30.89$ & $(14,80)$ & $11.13 \pm 4.38 \quad(6,16)$ & $312.6 \pm 206.99$ & $(147.4,615.4)$ & $0.1 \pm 0.14$ \\
\hline 2 January 2020 & $44.75 \pm 36.25$ & $(15,96)$ & $16.13 \pm 12.69(8,35)$ & $270.3 \pm 74.10$ & $(187.5,366.7)$ & $0.2 \pm 0.21$ \\
\hline 9 January 2020 & $53.25 \pm 29.39$ & $(26,88)$ & $19.75 \pm 9.03(12,32)$ & $261.6 \pm 55.57$ & $(185.7,319.0)$ & $0.0 \pm 0.05$ \\
\hline 16 January 2020 & $71.0 \pm 39.23$ & $(31,125)$ & $24.0 \pm 11.19(14,40)$ & $286.3 \pm 46.16$ & $(221.4,325.0)$ & $1.8 \pm 2.40(0.1,3.5)$ \\
\hline 20 January 2020 & $57.4 \pm 33.19$ & $(25,105)$ & $19.8 \pm 11.78 \quad(9,38)$ & $288.8 \pm 20.01$ & $(270.0,315.8)$ & $0.1 \pm 0.21 \quad(0,0.6)$ \\
\hline
\end{tabular}

Table 3. Dates for when the northern and southern transects were conducted, in addition to dates when the instrument sampled lead and frost flowers as well as first-year ice at the runway site.

\begin{tabular}{|c|c|c|c|c|}
\hline Date & $\begin{array}{c}\text { Northern } \\
\text { transect }\end{array}$ & $\begin{array}{l}\text { Southern } \\
\text { transect }\end{array}$ & $\begin{array}{l}\text { Lead and frost } \\
\text { flowers }\end{array}$ & $\begin{array}{l}\text { Runway - } \\
\text { first-year ice }\end{array}$ \\
\hline 7 November 2019 & $\mathrm{X}$ & & & \\
\hline 14 November 2019 & $\mathrm{X}$ & & & \\
\hline 23 November 2019 & & & $\mathrm{X}$ & \\
\hline 20 December 2019 & $\mathrm{X}$ & & & \\
\hline 26 December 2019 & $\mathrm{X}$ & $\mathrm{X}$ & & \\
\hline 2 January 2020 & $\mathrm{X}$ & $\mathrm{X}$ & & \\
\hline 9 January 2020 & $\mathrm{X}$ & $\mathrm{X}$ & & \\
\hline 12 January 2020 & & & & $\mathrm{X}$ \\
\hline 16 January 2020 & $\mathrm{X}$ & $\mathrm{X}$ & & \\
\hline 19 January 2020 & & & & $\mathrm{X}$ \\
\hline 23 January 2020 & & & $\mathrm{X}$ & \\
\hline 24 January 2020 & & & $\mathrm{X}$ & \\
\hline 30 January 2020 & $\mathrm{X}$ & $\mathrm{X}$ & & \\
\hline
\end{tabular}

RS site: 10 and 15 November, when the air (snow) temperatures were $-28^{\circ} \mathrm{C}\left(-28^{\circ} \mathrm{C}\right)$ and $-12^{\circ} \mathrm{C}\left(-8^{\circ} \mathrm{C}\right)$, respectively (Figs. 3 and 4). For the transects, we show preliminary results for the northern, southern and lead transects in order to highlight different snow and ice types. Figure 5 summarizes snow depth distributions for the northern (Fig. 5a) and southern (Fig. 5b) transects during January. Overall, the snow was deeper over SYI which was the dominant ice type for the northern transect compared to the southern transect which consisted in part also of FYI. Mean snow depths for the northern and southern transects ranged from 24.2 to $26.7 \mathrm{~cm}$ and from 19.6 to $22.2 \mathrm{~cm}$, respectively, from 2 to 30 January.

\subsection{Radar data processing}

During data acquisition, the KuKa radar acquires data in a series of six signal states: the four transmit polarization combinations (VV, HH, HV and VH), a calibration loop signal and a noise signal. Each data block consists of these six signals and is processed separately for each frequency. Data are processed into range profiles of the complex received voltage, through fast Fourier transform (FFT). The range profiles for each polarization combination are power-averaged in the azimuth for each incidence angle. In stare mode, the range profiles, gathered at nadir, are spatially averaged with 20 independent records averaged to reduce variance. For the scan mode, this procedure is done across the entire azimuthal angular width, for every incidence angle, $\theta$. To compute $\mathrm{Ku}-$ and Ka-band NRCS, we assume that all scattering is from the surface. We compute the illuminated scene by assuming an ellipse on the surface defined by the Ku- and Ka-band antenna beamwidth. However, since the range resolution is very fine, we sum the return power over many range gates in the region of the peak, usually starting with the first range gate at a level of $\sim 10-20 \mathrm{~dB}$ below the peak at nadir or the near range and ending at a similar level on the far-range side of the peak. The dominant contributing points to the total power are those points within $\sim 10 \mathrm{~dB}$ of the peak; therefore, the exact threshold level for beginning and ending the integration is not critical. This process should give the same power as would have been measured with a coarse-rangeresolution system having a single range gate covering the entire illuminated scene. From the averaged power profiles, the $\mathrm{Ku}-$ and Ka-band NRCS is calculated following Sarabandi et al. (1990) and given by the standard beam-limited radar range equation: 

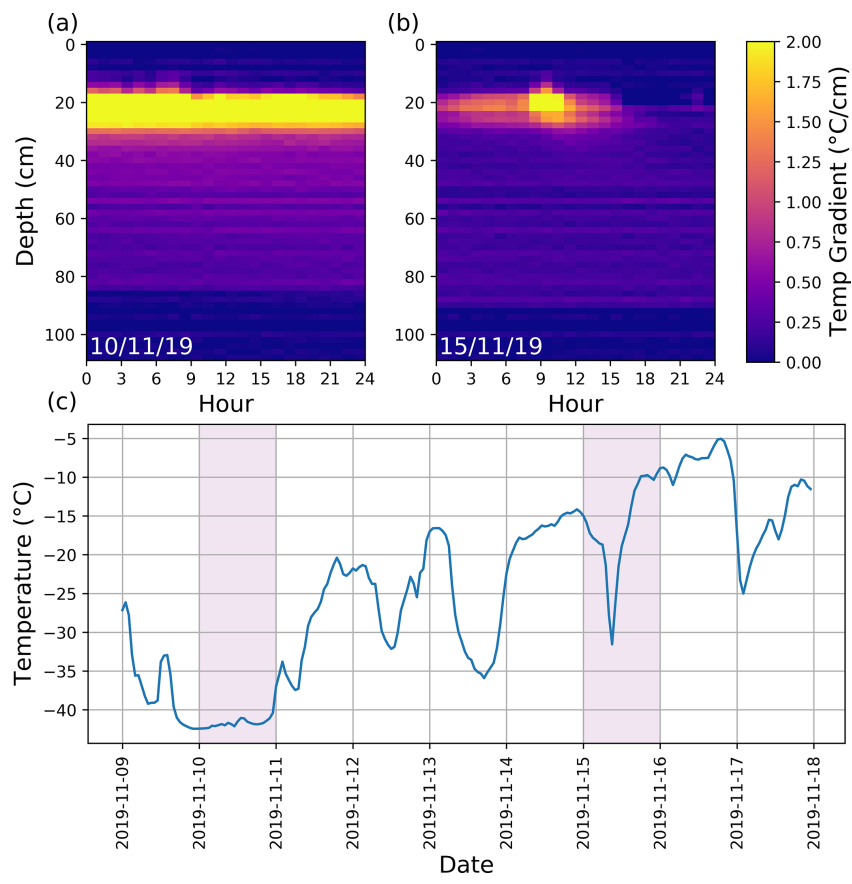

Figure 4. Hourly averaged near-surface, snow and sea ice temperature gradient from the RS site, acquired by thermistor strings on (a) 10 and (b) 15 November 2019. The top $20 \mathrm{~cm}$ represents the distance between the first temperature sensor located above the airsnow interface and the temperature sensor located at the air-snow interface. The bright yellow pixels represent the snow volume. The thermistor string was installed on 7 November 2019. (c) Hourly averaged snow surface temperature from the RS site between 10 and 15 November 2019, acquired by the TIR camera.

$\operatorname{NRCS} \sigma^{0}=\frac{8 \ln (2) h^{2} \sigma_{c}}{\pi R_{\mathrm{C}}^{4} \theta_{3 \mathrm{~dB}}^{2} \cos (\theta)}\left(\frac{\tilde{P}_{\mathrm{r}}}{\tilde{P}_{\mathrm{rc}}}\right)$,

where $h$ is the antenna height; $R_{\mathrm{C}}$ is the range to the corner reflector; $\theta_{3 \mathrm{~dB}}$ is the antenna's one-way half-power beamwidth; and $\tilde{P}_{\mathrm{r}}$ and $\tilde{P}_{\text {rc }}$ are the recorded power from the illuminating scene and the corner reflector, respectively. The process is the same for both frequencies, although the antenna footprints are not identical.

Copolarized $\left(\sigma_{\mathrm{VV}}^{0}\right.$ and $\left.\sigma_{\mathrm{HH}}^{0}\right)$ and cross-polarized $\left(\sigma_{\mathrm{HV}}^{0}\right.$ and $\sigma_{\mathrm{VH}}^{0}$, with $\sigma_{\mathrm{HV}}^{0} \sim \sigma_{\mathrm{VH}}^{0}$ assuming reciprocity) backscatter cross sections are then obtained for all four polarizations. The polarimetric parameters - copolarized ratio $\left(\gamma_{\mathrm{CO}}\right)$, crosspolarized ratio $\left(\gamma_{\text {CROSS }}\right)$, copolarized correlation coefficient $\left(\rho_{\mathrm{VVHH}}\right)$ and copolarized phase difference $\left(\varphi_{\mathrm{VVHH}}\right)-$ are also derived along with the polarimetric backscatter from the average covariance matrix (derived from the complex scattering matrix) of all azimuthal data blocks, within every incidence angle scan line, given by copol. ratio $\gamma_{\mathrm{CO}}=\frac{\sigma_{\mathrm{VV}}^{0}}{\sigma_{\mathrm{HH}}^{0}}$,

cross-pol. ratio $\gamma_{\mathrm{CROSS}}=\frac{\sigma_{\mathrm{HV}}^{0}}{\sigma_{\mathrm{HH}}^{0}}$,

copolarized correlation coefficient $\rho_{\mathrm{VVHH}}=$

$$
\left|\frac{\left\langle S_{\mathrm{HH}} S_{\mathrm{VV}}^{*}\right\rangle}{\sqrt{\left\langle S_{\mathrm{HH}} S_{\mathrm{HH}}^{*}\right\rangle\left\langle S_{\mathrm{VV}} S_{\mathrm{VV}}^{*}\right\rangle}}\right|,
$$

copolarized phase difference $\varphi_{\mathrm{VVHH}}=$

$$
\tan ^{-1}\left[\frac{\operatorname{Im}\left\langle S_{\mathrm{HH}} S_{\mathrm{VV}}^{*}\right\rangle}{\operatorname{Re}\left\langle S_{\mathrm{HH}} S_{\mathrm{VV}}^{*}\right\rangle}\right],
$$

where $S_{i j}$ comprises complex scattering matrix elements. Uncertainties in $\sigma^{0}$ estimation primarily arise from calibration error (multiplicative bias error due to presence of the metal tripod supporting the trihedral reflector), usage of a finite signal-to-noise ratio (SNR), standard deviation in estimated signal power (random error, as a function of number of independent samples and noise samples, and finite SNR), and errors due to approximations used for sensor and target geometry.

The linear FM signal for each polarization state has a duration of $2 \mathrm{~ms}$, followed by a $100 \mathrm{~ns}$ gap. Thus, the total time required to gather the data used in computing the complex received voltages is $8.3 \mathrm{~ms}$. To assure proper estimation of the copolarized correlation coefficient and phase difference, it is important that the antenna moves much less than half an antenna diameter during the time period between the VV and $\mathrm{HH}$ measurements $(2.1 \mathrm{~ms})$. Using an allowable movement of $1 / 20$ of the antenna diameter in $2.1 \mathrm{~ms}$, the maximum speed of the sled during the nadir measurements is limited to approximately $2.1 \mathrm{~m} / \mathrm{s}$ at the Ka-band and $3.5 \mathrm{~m} / \mathrm{s}$ at the Ku-band. The software provided by ProSensing converts the $\mathrm{Ku}-$ and Ka-band raw data in both stare and scan modes into calibrated polarimetric backscatter and parameters of the target covariance matrix and/or Mueller matrix. The $\mathrm{Ku}-$ and Ka-band signal processing, calibration procedure, derivation of polarimetric backscatter and parameters, and system error analysis are implemented similarly to the $\mathrm{C}$ - and $\mathrm{X}$-band scatterometer processing, built and implemented by ProSensing and described in detail by Geldsetzer et al. (2007) and King et al. (2012), respectively.

An experiment was done to investigate the response of the internal calibration loop in comparison to the instrument response when a metal plate was placed on the surface. This serves as a vertical height reference for the radar returns and demonstrates the response of the system to a flat, highly scattering surface. Figure 6 shows the experiment conducted with the metal plate for the Ka-band (Fig. 6a) and Ku-band (Fig. 6b). The metal plate and calibration loop data are consistent and in good agreement with each other (black and red, respectively), which indicates that the shape of the re- 

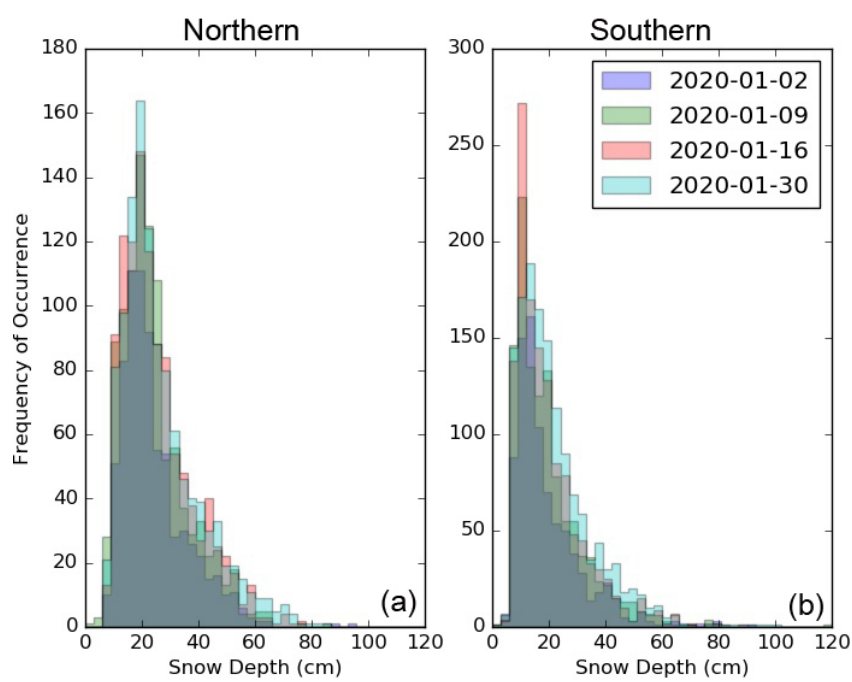

Figure 5. Snow depth distribution during January 2020 along the northern (a) and southern (b) transect loops.

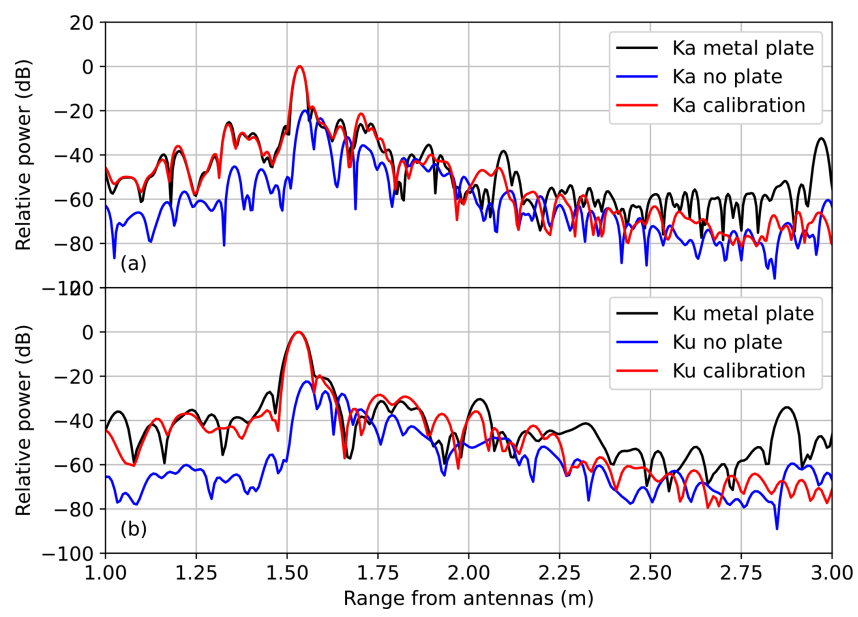

Figure 6. Radar returned power in the (a) Ka- and (b) Ku-bands. These data were gathered over the exposed snow and ice (blue); a metal plate on the snow surface, approximately $15 \times 55 \mathrm{~cm}$ (black); and the internal calibration loop (red). The calibration data have been shifted in range and power to correspond to the peak locations of the metal plate. The power that comes from above the air-snow interface within a few centimeters of the peak is simply the impulse response of the radar. The noisy power at the $-60 \mathrm{~dB}$ level is probably a range sidelobe of the signal from the peak region. The range sidelobes at the $-23 \mathrm{~dB}$ level and below (Ka-band) and at the $-30 \mathrm{~dB}$ level (Ku-band) are due to internal reflections in the radar system.

turn including internal reflections is well characterized in the calibration data. The blue data show the scattering from the exposed snow and ice (prior to placing the metal plate), to estimate the noise floor of the system. The range of the peak is slightly larger than for the metal plate data. We would expect this because the metal plate, approximately $15 \times 55 \mathrm{~cm}$ in size, did not fill all the footprints of the Ka- and Ku-band antennas, and the plate sits atop the highest points on the snow surface and has a finite thickness of $\sim 2 \mathrm{~cm}$. Therefore, its surface appears closer than the snow surface as it dominates the return: the measured peak range of the metal plate is $1.53 \mathrm{~m}$; when the plate is removed, the air-snow peak appears at about $1.55 \mathrm{~m}$ at both frequencies. The relative power is also much lower because the snow scatters light in more heterogeneous directions than the metal plate. From Fig. 6, uncontaminated by range sidelobes, the noise floor of the KuKa radar system before the snow surface return (around $1.4 \mathrm{~m}$ ) is estimated to be -70 and $-80 \mathrm{~dB}$ for $\mathrm{Ku}-$ band co- and cross-polarized channels, respectively, while for Ka-band, the noise floor is $-90 \mathrm{~dB}$ for all four polarization channels. The KuKa radar, via the internal calibration loop, is designed to track any gain variations except for those components which are outside the calibration loop, including the cables to the antenna and the antenna ports on the switches. This is the reason why frequent corner reflector calibrations are conducted when the instrument is deployed in different environments. The instrument manufacturer recommends external calibration once per deployment, to avoid instrument drifting due to hardware failure.

\section{Results and discussion}

\subsection{Altimeter stare mode}

We start with examples of $\mathrm{Ka}$ - and $\mathrm{Ku}$-band VV power (in $\mathrm{dB}$ ) along both the northern and the southern transect loops (Fig. 7) obtained on 16 January 2020. Results are shown as both the radar range from antenna (in meters) along with the VV power (in $\mathrm{dB}$ ) along a short transect distance; all radar range data in this paper are shown scaled with radiation propagating at the velocity of light in free space. Several key features are immediately apparent. For both $\mathrm{Ka}$ - and $\mathrm{Ku}$ bands, the dominant VV backscatter tends to originate from the air-snow interface, primarily due to a significant surface scattering contribution from this interface. The Ku-band signals also exhibit strong backscatter from greater ranges, which could correspond to volume scattering in the snow, layers with different dielectric properties caused by density inhomogeneities and/or the snow-sea ice interface. The key difference between the $\mathrm{Ka}$ - and $\mathrm{Ku}$-bands is that, owing to the shorter wavelength of the Ka-band, the attenuation in the snowpack is larger. Thus, compared to the $\mathrm{Ku}$-band, the dominant return from the Ka-band is expected to be limited to the air-snow interface, while the Ku-band penetrates further down through the snow volume and scatters at the snow-sea ice interface. In other words, the extinction (scattering + attenuation) in the snow in the Ka-band is higher than in the $\mathrm{Ku}$-band, and therefore, the snow-sea ice interface is hard to detect using the Ka-band. Note that the power that comes from above the air-snow interface within a few centimeters 
of the peak is the impulse response of the radar. The noisy power at the $-60 \mathrm{~dB}$ level is probably a range sidelobe of the signal from the peak region. All FMCW radars have range sidelobes, which are due to the nonideal behavior of the instrument as well as artifacts of the Fourier transform of a windowed signal. If the radar introduces no distortions, there will be a first sidelobe at a level of $-32 \mathrm{dBc}$ and a second sidelobe at a level of $-42 \mathrm{dBc}$ ( $\mathrm{dBc}$ being relative to the peak).

In this example, the local peak at the air-snow interface is generally stronger in the Ku-band than the local peak at the snow-ice interface, but this will depend strongly on the geophysical and thermodynamic state of the snowpack, including scatterer size, snow depth, density and composition (wind slab or metamorphic snow), snow salinity, and temperature (if the snowpack is saline). Snow and SYI properties from the northern transect were found to be similar to the three RS sites. Snow at the RS sites was consistently dry, cold (bulk snow temperature $\sim-25^{\circ} \mathrm{C}$ from all RS sites) and brine-free. Instances along the transect where the backscatter is greater at depth are apparent. Figure 7 also highlights the influence of snow depth on the backscatter, with less penetration and less multiple scattering observed for the data collected along the southern transect, which consisted of a mixture of FYI in refrozen melt ponds and intermittent SYI with an overall shallower snowpack. For the northern transect, the cross-polarized correlation coefficient (and indicator of the strength of multiple scattering) shows that multiple scattering is dominating from a depth of below $1.8 \mathrm{~m}$ in the Ka-band and from a depth of below $2.2 \mathrm{~m}$ in the $\mathrm{Ku}-$ band (not shown). There is considerably less multiple scattering in the southern transect data. However, further research is necessary to determine which type of multiple scattering (e.g., volume-surface, surface-surface or volume-volume) is dominant from the signal contributions; and this is beyond the scope of this paper.

Figure 8 shows the average of the range profile of VVand $\mathrm{HH}$-polarized signal power for the same date and time as in Fig. 7 yet processed for two different locations along the same transect segment (see figure caption). The range displayed is limited to $3.0 \mathrm{~m}$, and the figure shows data in zoomed-in sections of a $6 \mathrm{~m}$ width $(6 \mathrm{~m}$ of travel along the transect). Only independent samples are included, where the speed of the sled is at least $0.4 \mathrm{~m} / \mathrm{s}$. In Fig. 8a, both Ku- and Ka-bands have a peak return between 1.5 and $1.6 \mathrm{~m}$, with a peak HH backscatter of -20.8 and $-30.2 \mathrm{~dB}$, respectively (VV backscatter is similar at -20.6 and $-29.7 \mathrm{~dB}$ ). Power is also returned in the Ku-band at a range of approximately $2.0 \mathrm{~m}$. This could be a strong return either from the snowice interface or from ice layers and a highly dense wind slab within the snowpack. The shallow slope of the tail of the Kuband waveform suggests volume scattering and/or multiple scattering from the upper layers of the snow volume, whereas the tail falls off faster for the Ka-band.

Figure $8 \mathrm{~b}$ is an example further along the transect; at the Ku-band, there are three peaks corresponding to ranges be- tween 1.5 and $1.75 \mathrm{~m}$ (first peak at $1.52 \mathrm{~m}$, second and third peaks at 1.66 and $1.73 \mathrm{~m}$, respectively). There is also power returned from $1.94 \mathrm{~m}$. This peak is $42 \mathrm{~cm}$ below the first peak, which could correspond to the snow-ice interface. Snow depths from the Magnaprobe ranged from a shallow $7 \mathrm{~cm}$ to as deep as $53 \mathrm{~cm}$, with a mean depth of $23 \mathrm{~cm}$ (median of $19 \mathrm{~cm}$ ). Note, however, that the peak separations stated here assume the relative dielectric constant is 1.0. Given the bulk snow densities, ranging from 256.5 to $312.6 \mathrm{~kg} / \mathrm{m}^{3}$, wave propagation speed was calculated to be around $80 \%$ of the speed in a vacuum. Therefore, the separation between peaks at a greater range than the air-snow interface is around $80 \%$ of what it appears to be in the data as shown here, where all data are scaled for the speed of light in free space.

For the shallower snow cover over the southern transect shown in Fig. 8 at $26-31 \mathrm{~m} \mathrm{(c)} \mathrm{and} 150-156 \mathrm{~m} \mathrm{(d),} \mathrm{there} \mathrm{is}$ less multiple scattering within the snow and the long tail falls off faster. In the examples shown, the dominant backscatter at both $\mathrm{Ka}-$ and $\mathrm{Ku}$-bands comes from the air-snow interface, with the Ku-band and Ka-band in Fig. 8d also picking up a secondary peak between 1.6 and $1.8 \mathrm{~m}$, which could correspond to the snow-sea ice interface. The Magnaprobe data along this portion of the transect had mean and median snow depths of 13 and $11 \mathrm{~cm}$, respectively.

These VV (and HH) data demonstrate the potential for detailed comparisons between KuKa data and coincident datasets such as Magnaprobe snow depth and snow microstructure profiles from SMP measurements to explore the scattering characteristics in the Ka- and Ku-bands, over varying snow and ice conditions. Further insight is gained by overlaying the Magnaprobe snow depth (Fig. 9 for the northern transect). To make this comparison, both the KuKa and Magnaprobe data have been corrected using the FloeNavi script developed by Hendricks (2020), which converts latitude, longitude and time data into floe coordinates, referenced to the location and heading of the Polarstern. The data along the transect were then divided into $5 \mathrm{~m}$ sections, and in each section the snow depth (from the Magnaprobe), $\mathrm{Ku}-$ band echoes and Ka-band echoes were averaged and plotted as shown in Fig. 9 which shows the averaged echoes with average snow depths overlaid. Also shown is the first peak identified using a simple peak detection method that corresponds to the snow-air interface. Of note is that there appears to be agreement between the first peaks detected in the Kaand $\mathrm{Ku}$-bands and between peaks in the Ku-band echoes and the Magnaprobe snow depths (which have been scaled by 0.8 to take into consideration the slower wave propagation speed into the snow). Overall, the mean power at the air-snow interface (as picked by the algorithm) is -31 and $-20 \mathrm{~dB}$ for the Ka- and Ku-band, respectively, both with a standard deviation of $3 \mathrm{~dB}$. The mean power at the Magnaprobe-derived snow depths is -45 and $-30 \mathrm{~dB}$ for the Ka- and Ku-band, respectively, with a standard deviation of $6 \mathrm{~dB}$. The mechanisms whereby $\sigma_{\mathrm{VV}}^{0}$ increases at the snow-ice interface and correlations between snow depth and this peaks will be fur- 

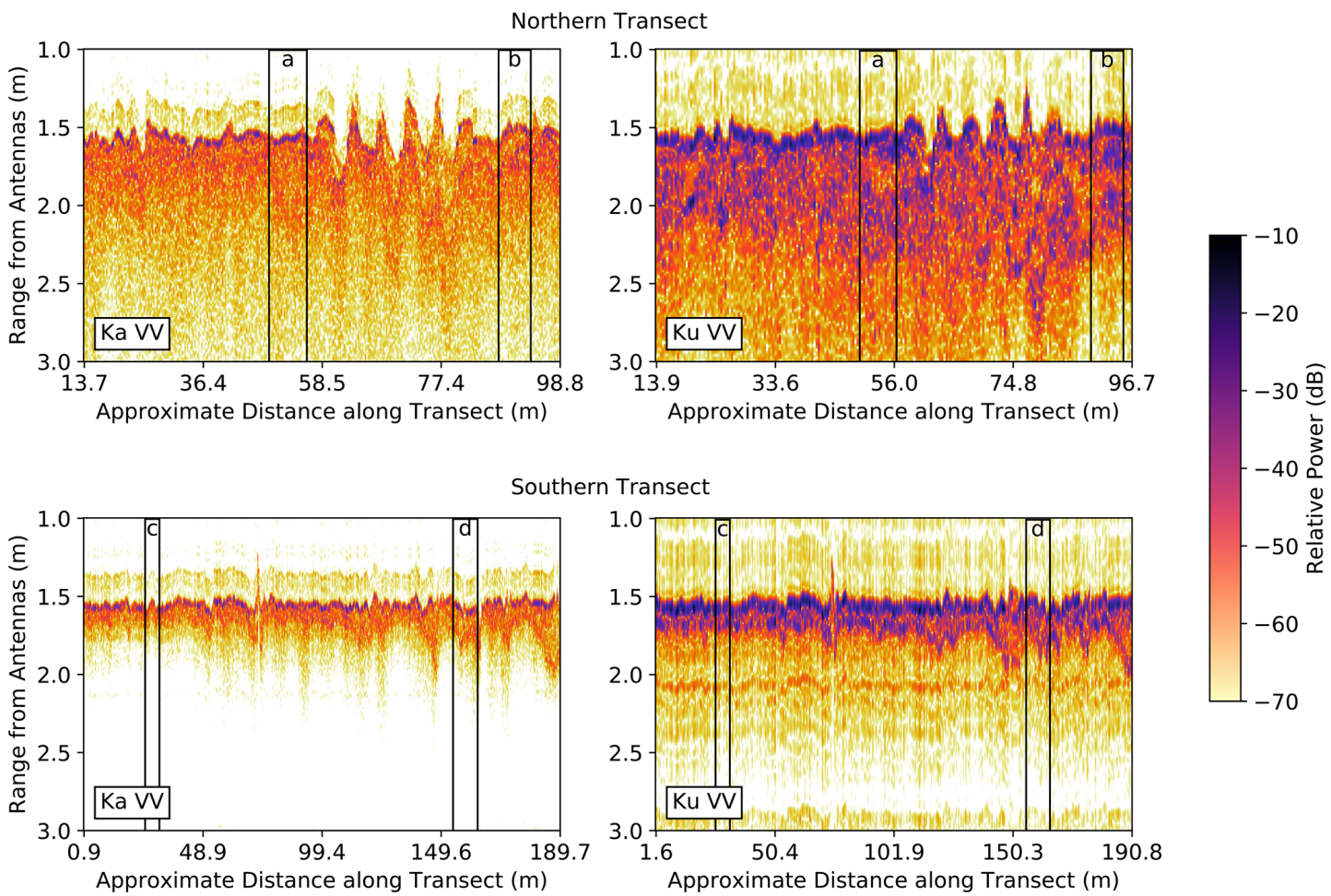

Figure 7. Ka- (left) and $\mathrm{Ku}$ - (right) band VV-polarized power as a function of distance along the northern (top) and southern (bottom) transect. Data acquired on 16 January 2020 at 10:52 and 12:02 UTC for the northern and southern transects, respectively. Letters a-d denote four sections shown in more detail in Fig. 8, each $6 \mathrm{~m}$ wide (corresponding to $6 \mathrm{~m}$ of travel along the transect). Data are not evenly spaced along the $x$ axis; tick marks indicate distances along the transect where the samples were obtained.

ther investigated and quantified in a publication which will analyze these data in detail.

Finally, we show the example of backscatter from the highly saline, refrozen lead covered by frost flowers sampled on 24 January 2020 when the ice was approximately $10 \mathrm{~cm}$ thick (Fig. 10). As expected, there is a strong backscatter return from the rough effective air-sea ice interface surface produced by brine wicking in the frost flowers at both $\mathrm{Ka}$ - and Ku-bands, with little scattering below the lead surface. Coincident to the radar measurements, we also measured frost flower and ice salinities at $1 \mathrm{~cm}$ resolutions. The top $1 \mathrm{~cm}$ salinity was $\sim 36 \mathrm{ppt}$, and the bulk ice salinity was $\sim 10$ ppt (not shown). These high salinities are expected to mask the propagation of $\mathrm{Ka}-$ and $\mathrm{Ku}$-bands signals reaching the ice-water interface.

\subsection{Scatterometer scan mode}

The observed hourly averaged Ka- and Ku-band $\sigma_{\mathrm{VV}}^{0}, \sigma_{\mathrm{HH}}^{0}$ and $\sigma_{\mathrm{HV}}^{0}$ and derived polarimetric parameters $\gamma_{\mathrm{CO}}, \gamma_{\mathrm{CROSS}}$, $\varphi \mathrm{VVHH}$ and $\rho_{\mathrm{VVHH}}$ from the snow-covered SYI, acquired on 10 and 15 November 2019, are presented in Fig. 11a to e, to illustrate the polarimetric backscatter and parameter variability, as a function of $\theta$. Errors bars for the Ka- and Ku-band $\sigma_{\mathrm{VV}}^{0}, \sigma_{\mathrm{HH}}^{0}$ and $\sigma_{\mathrm{HV}}^{0}$ are displayed as standard deviations of the backscatter, as a function of the incidence angle, throughout the hourly scans. The standard deviation of $\gamma_{\mathrm{CO}}, \gamma_{\mathrm{CROSS}}$ and $\varphi_{\mathrm{VVHH}}$ are estimated from the probability density functions of these parameters, following Geldsetzer et al. (2007) and Lee et al. (1994), while variability in $\rho_{\mathrm{VVHH}}$ is displayed as a minimum-maximum range.

\subsubsection{Ka- and Ku-band $\sigma_{\mathrm{VV}}^{0}, \sigma_{\mathrm{HH}}^{0}$ and $\sigma_{\mathrm{HV}}^{0}$}

Figure 11a and b illustrate Ka- and Ku-band $\sigma_{\mathrm{VV}}^{0}, \sigma_{\mathrm{HH}}^{0}$ and $\sigma_{\mathrm{HV}}^{0}$ signatures from a homogenous $12 \mathrm{~cm}$ snow-covered refrozen melt-ponded SYI, acquired on 10 and 15 November 2019, as air (near-surface) temperature increased from $-28^{\circ} \mathrm{C}\left(-35^{\circ} \mathrm{C} ; 10\right.$ November $)$ to $-12{ }^{\circ} \mathrm{C}\left(-12{ }^{\circ} \mathrm{C} ; 15\right.$ November), measured from the ship (Fig. 3) and the RSsite-installed DTC (Fig. 4a, b), respectively. The increase in air and near-surface temperature between 10 and 15 November occurred during a minor storm event with $\sim 15 \mathrm{~m} / \mathrm{s}$ wind speed and corresponding snow redistribution. Between 10 and 15 November, our results demonstrate an increase in $\mathrm{Ka}$ - and $\mathrm{Ku}$-band $\sigma_{\mathrm{VV}}^{0}$ and $\sigma_{\mathrm{HH}}^{0}$ by $\sim 6$ and $\sim 3 \mathrm{~dB}$, respectively. The steep increase in backscatter is prominent at nadirto near-range $\theta$ of $\sim 5^{\circ}$ (Ka-band) and $\sim 10^{\circ}$ (Ku-band). Variability and increase in nadir- and near-range backscatter can be attributed to an increase in either surface scattering 


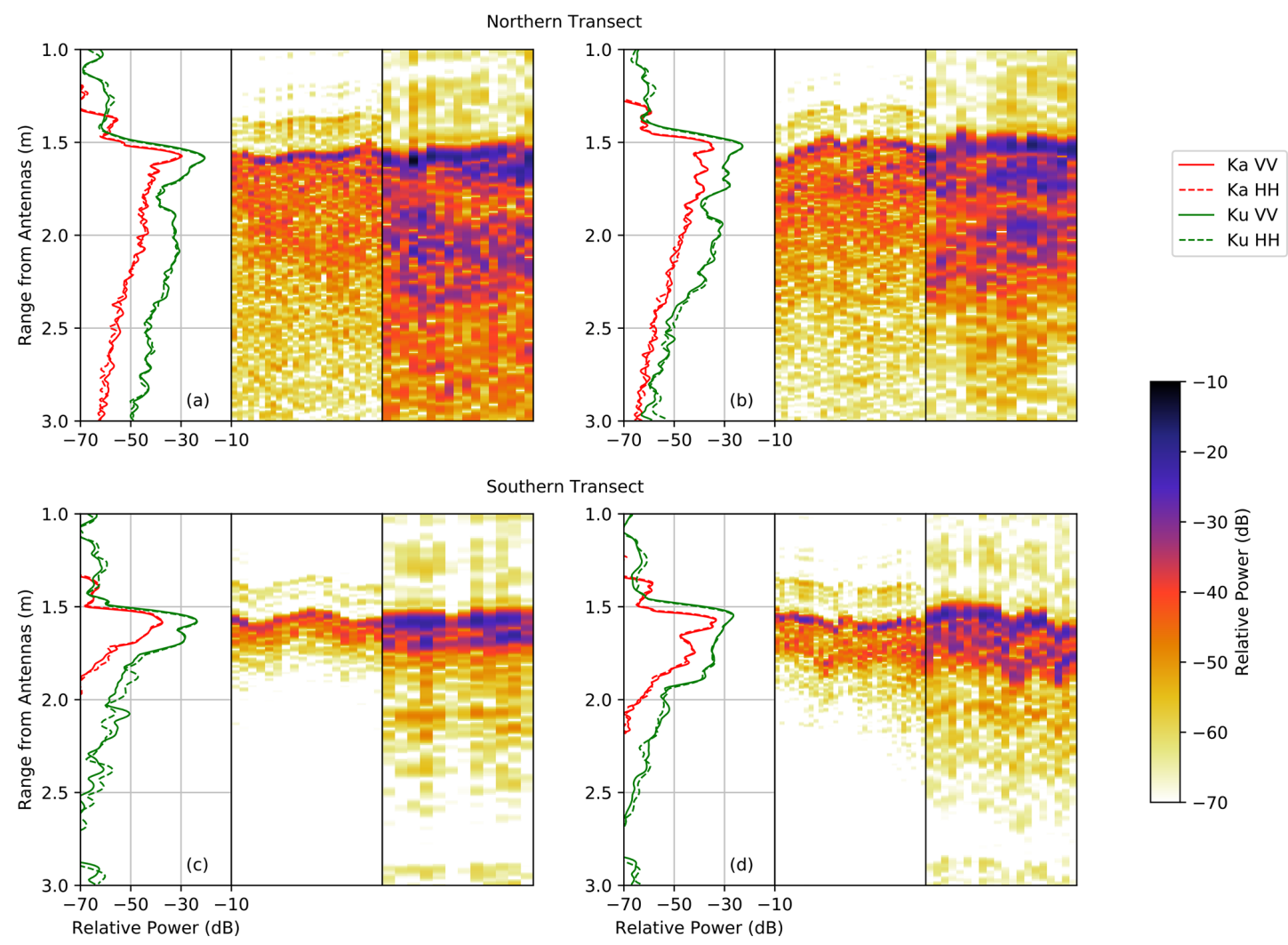

Figure 8. Average VV- and HH-polarized signal power as a function of range at the Ka-band (middle panels) and Ku-band (right panels) for specific locations along the northern $(\mathbf{a}, \mathbf{b})$ and southern $(\mathbf{c}, \mathbf{d})$ transects as shown in Fig. 7. The difference in the average spectrum between $(\mathbf{a}, \mathbf{b})$ and $(\mathbf{c}, \mathbf{d})$ is that they are from different locations along the transect and highlight the influence of multiple scattering in the snow and a return from what could be the snow-ice interface at the Ku-band.

(denser or smoother snow surface or smoother ice surface at nadir) or volume scattering (larger snow grains), also potentially leading to variations in $\mathrm{Ku}$ - and Ka-band radar penetration depth between the cold and the warm day. Temperatures, influencing snow metamorphosis (snow grain growth) and changes in dry-snow properties like surface roughness, e.g., from erosion, deposition or wind compaction, can result in increased backscatter within the scatterometer footprint. Snow surface temperatures from the radar footprint measured from the TIR camera (installed next to the radar system) recorded an increase in the snow surface temperatures from $\sim-28^{\circ} \mathrm{C}(10$ November $)$ to $\sim-8^{\circ} \mathrm{C}(15$ November; Fig. 4c). These changes observed from the TIR camera are consistent with the near-surface and snow surface temperatures measured by the DTC, installed next to the RS site (Fig. 4a, b).

Overall, the copolarized backscatter magnitude is higher at nadir and near-range $\theta$, for both Ka- and Ku-bands, and demonstrates a steady decline at mid- and far-range $\theta$, especially for the Ku-band. However, at $\theta>35^{\circ}$, Ka-band $\sigma_{\mathrm{VV}}^{0}$ and $\sigma_{\mathrm{HH}}^{0}$ show a characteristic increase by $\sim 3 \mathrm{~dB}(15$ November) and $5 \mathrm{~dB}$ (10 November), likely due to strong volume scattering from the topmost snow surface, with the footprint covered at far-range $\theta$ likely to be spatially less homogenous. However, more analysis using snow and sea ice geophysical properties, including snow redistribution and surface roughness changes as well as meteorological conditions, is required in this regard and is outside the scope of this paper. The error for the copolarized backscatter ranges between $\pm 2.1 \mathrm{~dB}$ (Ka-band) and $\pm 1.9 \mathrm{~dB}$ (Ku-band) at nadirand near-range $\theta$ and decreases to $\pm 2.0 \mathrm{~dB}$ (Ka-band) and $\pm 1.7 \mathrm{~dB}$ (Ku-band) at mid- and far-range $\theta$. The KuKa radar demonstrates and maintains a high SNR across a large range of $\theta$ angles, gradually decreasing with increasing $\theta$. At nadir, the copolarized SNRs are observed to be $\sim 85 \mathrm{~dB}$ (Ka-band) and $\sim 65 \mathrm{~dB}$ (Ku-band), while at far-range $\theta$, SNRs decrease to $\sim 80 \mathrm{~dB}$ (Ka-band) and $\sim 55 \mathrm{~dB}$ (Ku-band). These ranges are consistent for measurements acquired during the cold and warm periods on 10 and 15 November, respectively. Even though system error can influence the observed $\mathrm{Ku}$ - and $\mathrm{Ka}-$ band backscatter variability, spatial variability in the snow surface within the radar footprint may also add to the error estimates, especially at steep $\theta$ angles with a lower number of independent samples.

In the case of cross-polarized backscatter $\sigma_{\mathrm{HV}}^{0}$, Ka-band backscatter is dominant throughout the $\theta$ range, with an 

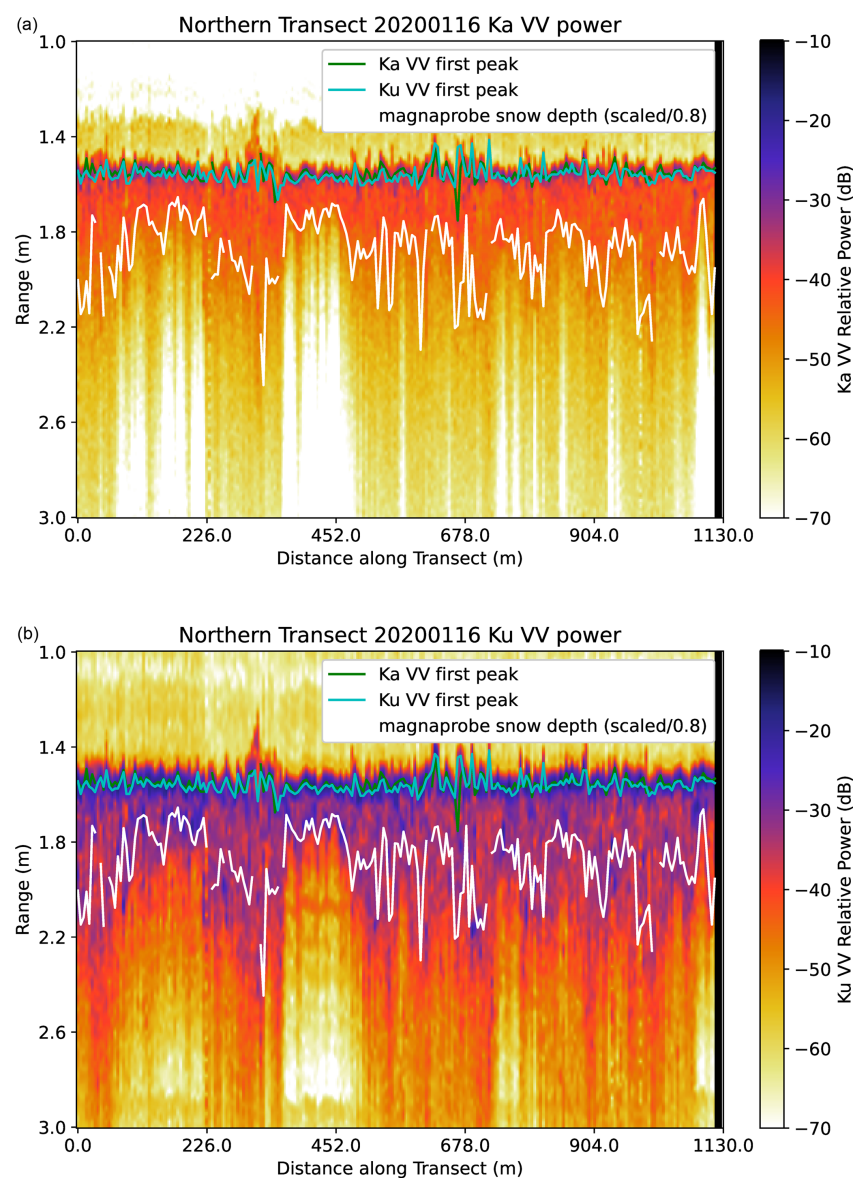

Figure 9. $\mathrm{Ka}$ (a) and $\mathrm{Ku}$ (b) VV power along the northern transect on 16 January 2020 . The data have been corrected for ice motion to allow intercomparison between KuKa and Magnaprobe data gathered from 10:46 to 12:17 and 10:36 to 12:44 UTC, respectively. The transect has been divided into $5 \mathrm{~m}$ sections; for each section the averaged KuKa echoes and Magnaprobe snow depth data are shown. The green and cyan lines indicate the ranges of the first peaks detected in the $\mathrm{Ka}$ and $\mathrm{Ku}$ echoes, respectively. The white line indicates the snow depth (from nearby Magnaprobe data) plotted with depths measured from the Ka VV first peak for each echo and divided by 0.8 for comparison with the radar data, to account for the slower EM radiation propagation of the radar in snow relative to free space.

$\sim 10 \mathrm{~dB}$ increase in $\sigma_{\mathrm{HV}}^{0}$, compared to Ku-band $\sigma_{\mathrm{HV}}^{0}$, on both 10 and 15 November. This substantial increase in Ka-band $\sigma_{\mathrm{HV}}^{0}$ indicates a strong volume scattering contribution from the topmost snow layers, compared to lower Ku-band volume scattering from within the penetrable snow volume within the snowpack. For both Ka- and Ku-bands, overall, the $\theta$ dependence on $\sigma_{\mathrm{HV}}^{0}$ is mostly negative, with both frequencies exhibiting a steady decline with $\theta$. However, Ku-band dependence is slightly more negative than that of the Kaband at near-range $\theta$ and is followed by a slight increase in the midrange and then by slightly negative dependence at far-range $\theta$. In addition, both Ka- and Ku-band $\sigma_{\mathrm{HV}}^{0}$ SNRs are lower, compared to $\sigma_{\mathrm{VV}}^{0}$ and $\sigma_{\mathrm{HH}}^{0}$ SNRs, at $\sim 75 \mathrm{~dB}$ (Ka-band) and $\sim 50 \mathrm{~dB}$ (Ku-band) at nadir, and decreases to $\sim 70 \mathrm{~dB}$ (Ka-band) and $\sim 45 \mathrm{~dB}$ (Ku-band), at far-range $\theta$. Between Ka- and Ku-band $\sigma_{\mathrm{HV}}^{0}$ signatures from 10 and 15 November, both frequencies demonstrate only an $\sim 2 \mathrm{~dB}$ difference, consistently throughout the $\theta$ range. Detailed analysis of all the polarimetric backscatter signatures from both frequencies are outside the scope of this paper.

\subsubsection{Ka- and Ku-band $\gamma_{\mathrm{CO}}, \gamma_{\mathrm{CROSS}}, \varphi_{\mathrm{VVHH}}$ and $\rho$ VVHH}

The copolarized ratio $\gamma_{\mathrm{CO}}$ demonstrates little difference between $\sigma_{\mathrm{VV}}^{0}$ and $\sigma_{\mathrm{HH}}^{0}$ for both Ka- and Ku-bands, for both 10 and 15 November observations (Fig. 11c). At $\theta>20^{\circ}$, Ku-band $\gamma_{\mathrm{CO}}$ illustrates a slightly higher magnitude at $\sigma_{\mathrm{VV}}^{0}$ over $\sigma_{\mathrm{HH}}^{0}$. These observations are consistent with scattering models assuming isotropic random media (Lee et al., 1994) and are similarly observed in MYI observations from a C-band scatterometer system (Geldsetzer et al., 2007). The cross-polarized ratio $\gamma_{\text {CROSS }}$ shows a characteristic shift in the Ka-band when compared to the Ku-band, especially at nadir to $5^{\circ}$, where Ka-band $\sigma_{\mathrm{HH}}^{0}$ dominates over $\sigma_{\mathrm{HV}}^{0}$ on 15 November (Fig. 11d). This suggests strong surface scattering from the denser or smoother snow surface or smoother ice surface at nadir. With increasing $\theta$, the Ka-band $\gamma_{\text {CROSS }}$ demonstrates greater $\sigma_{\mathrm{HV}}^{0}$, suggesting potential volume scattering from the upper layers of the snowpack, on both 10 and 15 November. Ku-band $\gamma_{\text {CROSS }}$ demonstrates the same behavior as the Ka-band till $\theta=15^{\circ}$, after which the crosspolarization ratio remains unchanged on both the cold and the warm day. The copolarized phase difference $\varphi \mathrm{VVHH}$ for both Ka- and $\mathrm{Ku}$-bands clearly demonstrates variability in phase shifts between the cold and warm days, especially at mid- and far-range $\theta$ (Fig. 11e). The higher Ka-band frequency decorrelates and undergoes higher positive phase shifts, deviating from zero, compared to the lower-frequency Ku-band on both 10 and 15 November. This suggests significant Ka-band anisotropy from the snow surface between the cold and warm day, while the lower phase difference at the Ku-band indicates isotropic scattering, possibly from randomly distributed, nonspherical scatterers (Nghiem et al., 1990; Nghiem et al., 1995; Drinkwater et al., 1995). Also note the large shift in Ka-band $\varphi$ VVHH towards positive values, at $\theta>20^{\circ}$ on 15 November, which indicates potential of second- or multiple-order scattering within the snowpack, likely caused by surface roughness changes. This characteristic is less prominent from the Ku-band $\varphi \mathrm{VVHH}$. The complex copolarized correlation coefficient $\rho_{\mathrm{VVHH}}$ values are closer to 1 for both Ka- and Ku-bands, at nadir- and near-range $\theta$, on both 10 and 15 November (Fig. 11f). The $\rho$ VvHH values from 15 November are slightly higher than from 10 November, suggesting increased $\mathrm{Ka}$ - and $\mathrm{Ku}$-band surface scattering at these angles during the warm day. Similarly to the polari- 

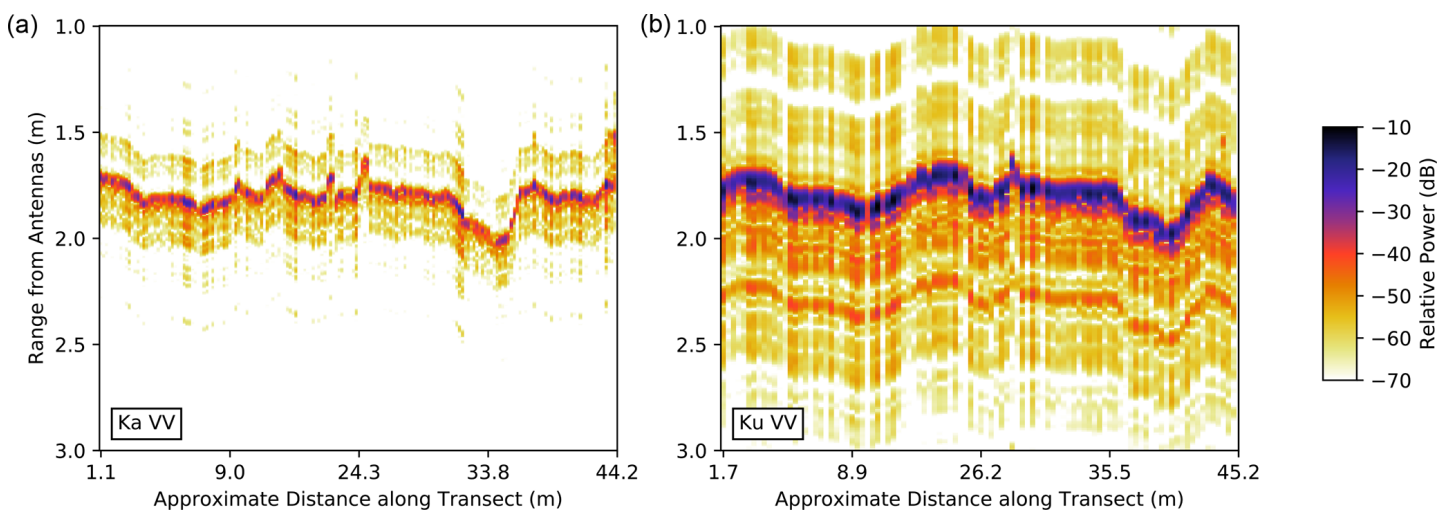

Figure 10. Ka- (a) and $\mathrm{Ku}$ - (b) band VV-polarized signal power as a function of distance along the refrozen lead. Data acquired on 24 January 2020 at 12:41 UTC.

metric backscatter signatures, detailed analysis of polarimetric parameters is beyond the scope of this paper.

Overall, the KuKa radar system operating in the scatterometer mode is able to characterize changes in polarimetric backscatter and derived parameters, following variations in meteorological and snow geophysical changes during a snow warming event in the middle of the winter thermodynamic regime. Prominent changes in Ku- and Ka-band backscatter and derived parameters are observed at nadir and near-range incidence angles, exemplifying the importance for snow and sea ice state variables of satellite radar altimetry. In a warming Arctic, with potential warming and storm events occurring within the winter regime, the surface-based KuKa radar was sensitive to geophysical changes on snow-covered sea ice. This also means both frequencies may potentially exhibit varying penetration depths between the cold and warm days, influencing the accuracy of satellite-derived snow depth retrievals from dual-frequency approaches. On the other hand, changes in backscatter and parameters throughout the incidence angle range provide first-hand baseline knowledge of $\mathrm{Ku}-$ and Ka-band backscatter behavior from snow-covered sea ice and its associated sensitivity to changes in snow and sea ice geophysical and thermodynamic properties. This is important to apply on future Ku- and Ka-band satellite SAR and scatterometer missions for accurately retrieving critical snow and sea ice state variables, such as sea ice freeze- and melt-onset timings or sea ice type classification.

\section{Conclusions}

Satellite remote sensing is the only way to observe long-term pan-Arctic sea ice changes. Yet satellites do not directly measure geophysical variables of interest, and therefore comprehensive understanding of how electromagnetic energy interacts within a specific medium, such as snow and sea ice, is required. During the MOSAiC expedition, we had the unique opportunity to deploy a surface-based, fully polarimetric,
$\mathrm{Ku}$ - and Ka-band dual-frequency radar system (KuKa radar), together with detailed characterization of snow, ice and atmospheric properties, to improve our understanding of how radar backscatter at these two frequencies varies over a full annual cycle of sea ice growth, formation and decay. We were also able to collect observations in the central Arctic during a time of the year (winter) when in situ validation data are generally absent.

During the autumn (leg 1) and winter (leg 2) of the MOSAiC drift experiment, the instrument sampled refrozen leads, first-year and second-year ice types, and refrozen melt ponds. These data thus provide a unique opportunity to characterize the autumn-to-winter evolution of the snowpack and its impact on radar backscatter and radar penetration, including the evolution of brine wetting on snow-covered firstyear ice, providing a benchmark dataset for quantifying error propagation in sea ice thickness retrievals from airborne and satellite-borne radar sensors. Our observations from the transect measurements over second-year ice illustrate the potential of the dual-frequency approach to estimate snow depth on second-year sea ice, under cold and dry (nonsaline) snow geophysical conditions, during the winter season. In thin-ice and first-year-ice conditions, with thin and saline snow covers, our initial assessments show distinct differences in radar scattering horizons at both Ka- and Ku-band frequencies. Detailed analysis, combining snow pit and Magnaprobe data with all the transect data collected, is outside the scope of the present paper and will form the basis of future work. In particular, future analyses will focus on comparisons between the KuKa radar data and simulations, driven by in situ snow and sea ice geophysical properties and meteorological observations, in order to attribute the peaks and volume scattering to physical surfaces and volumes. Data to be collected during the melt onset and freeze-up are forthcoming and should offer further insights into radar-scattering-horizon variability during these critical transitions.

The dual-frequency KuKa system also illustrates the sensitivity in polarimetric backscatter and derived parameters 

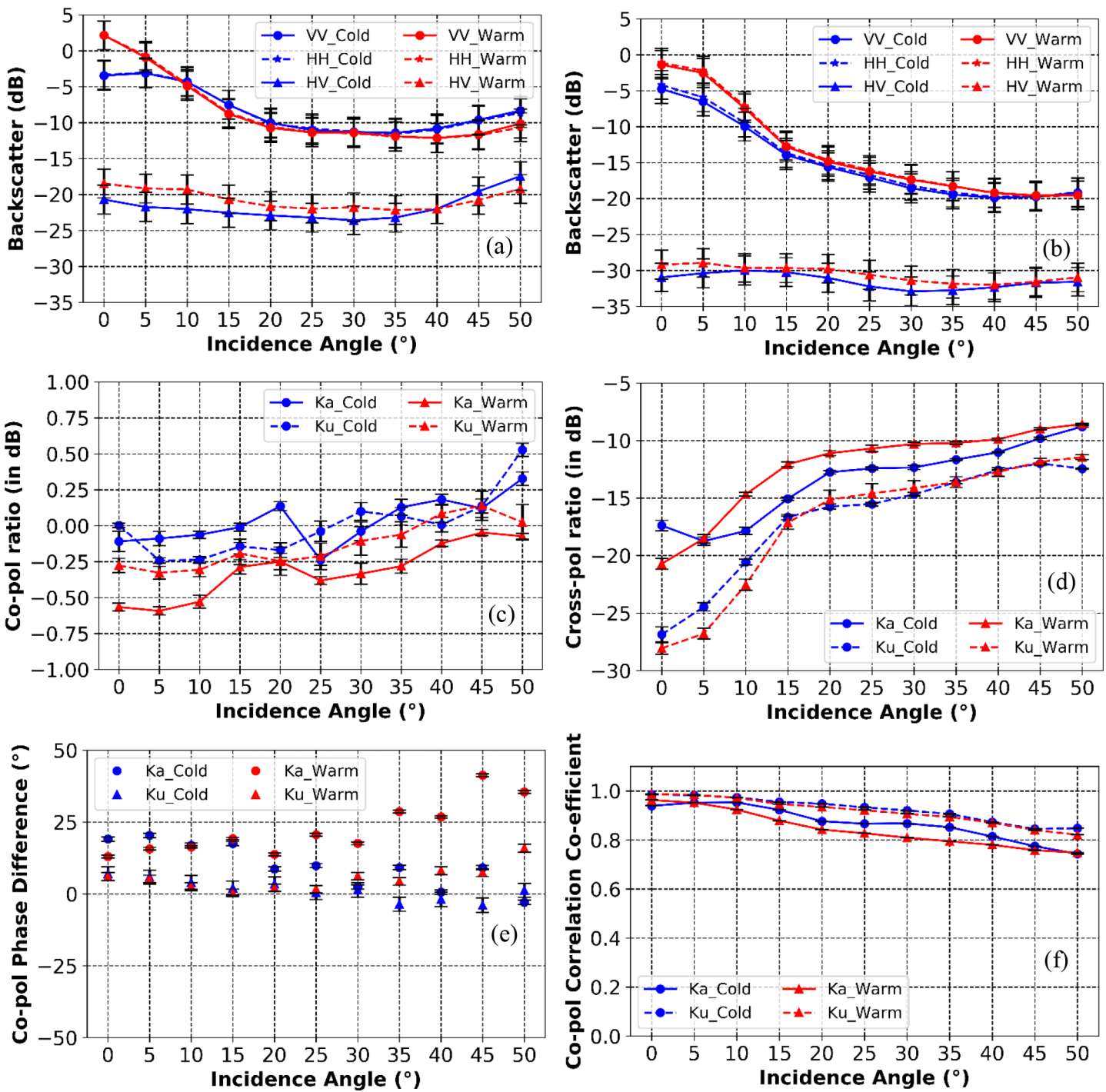

Figure 11. Ku- and Ka-band polarimetric backscatter and parameters from snow-covered sea ice from the RS site acquired on 10 November (cold) and 15 November (warm) 2019. (a) Ka-band co- and cross-polarized backscatter $\sigma_{\mathrm{VV}}^{0}, \sigma_{\mathrm{HH}}^{0}$ and $\sigma_{\mathrm{HV}}^{0}$; (b) Ku-band co- and crosspolarized backscatter $\sigma_{\mathrm{VV}}^{0}, \sigma_{\mathrm{HH}}^{0}$ and $\sigma_{\mathrm{HV}}^{0}$; (c) copolarized ratio $\gamma_{\mathrm{CO}}$; (d) cross-polarized ratio $\gamma_{\mathrm{CROSS}}$; (e) copolarized phase difference $\varphi_{\mathrm{VVHH}}$; and (f) copolarized correlation coefficient $\rho_{\mathrm{VVHH}}$. Fit lines are cubic for backscatter, and error bars represents standard deviation. Fit lines for copolarized ratio, cross-polarized ratio and copolarized correlation coefficient are quadratic. Errors bars for these parameters represent standard deviation (copolarized and cross-polarized ratio) and min-max (copolarized correlation coefficient). Error bars for copolarized phase difference represent standard deviation.

to changes in snow geophysical properties (example from 10 and 15 November observations used in this study). For the first time, the radar system was able to characterize prominent changes in $\mathrm{Ku}$ - and Ka-band radar signatures between cold (10 November) and warm (15 November) periods, especially at the nadir incidence angle, exemplifying the impact of accurate snow and sea ice state variable retrievals (e.g., snow depth) from satellite radar altimetry. Through illustrating changes in $\mathrm{Ku}$ - and Ka-band polarimetric backscatter and derived parameters between the cold and warm period, the dual-frequency approach shows promise in characterizing frequency-dependent temporal changes in polarimetric backscatter from snow-covered sea ice, as a function of the incidence angle, applicable for future $\mathrm{Ku}$ - and Ka-band satellite SAR and scatterometer missions. By utilizing a frequency-dependent polarimetric parameter index such as the "dual-frequency ratio" developed by Nandan et al. (2017c), the KuKa system will be able to reveal characteristic temporal changes in polarimetric backscatter, as a function of snow depth and sea ice type, polarization, frequency, and the incidence angle, as the snow-sea ice system thermodynamically evolves between freeze-up to spring melt onset. 
Moving forward, new space borne $\mathrm{Ku}$ - and Ka-band radar altimeter and SAR satellites such as ESA's CRISTAL mission (to name just one) are proposed to be launched in the near future. While the signals received from a satellite altimeter are in the far field of the antenna, in contrast to the signals from the KuKa radar in the near field, the in situbased radar system can provide important insights into the interaction of the radar signals with the range of physically different surfaces encountered on sea ice floes. Our findings from this study and forthcoming papers will facilitate significant improvements in already existing $\mathrm{Ku}$ - and Ka-band dual-frequency algorithms to accurately retrieve snow depth and sea ice thickness from these above-mentioned satellites. Datasets acquired from these forthcoming satellites will also provide a valuable source for downscaling surface-based estimates of snow depth on sea ice from the KuKa system to the "satellite scale" and validate new or similar existing findings.

Data availability. Data are available at the NERC data center (https://doi.org/10.5285/5FB5FBDE-7797-44FA-AFA64553B122FDEF, Stroeve et al., 2020b). On 1 January 2023, all MOSAiC data will be made publicly available with a citable DOI in a certified data repository following the FAIR Data Principles.

Supplement. The supplement related to this article is available online at: https://doi.org/10.5194/tc-14-4405-2020-supplement.

Author contributions. JS conceptualized the design of $\mathrm{KuKa}$, acquired funding for the MOSAiC expedition and the building of the $\mathrm{KuKa}$ radar, participated in the data collection during leg 2, performed analysis of transect data, and wrote the manuscript. VN participated in the MOSAiC leg 2 expedition, processed and performed analysis of the scatterometer mode data, and provided reviews and editing. RW performed the transect data processing, visualization and analysis for intercomparison with Magnaprobe and KuKa data, and paper review and editing. JM designed and built the KuKa radar, provided software for data processing, and provided reviews and editing. RT, MH, SH, RR, PI and MS helped with data collection, reviewing and editing. DK, IM and $\mathrm{MH}$ helped with data collection. RM analyzed thermistor string data and provided data visualization. JW and MT are co-investigators on the NERC grant that funded the work.

Competing interests. The authors declare that they have no conflict of interest.

Acknowledgements. This work was funded in part through NERC grant no. NE/S002510/1, the Canada 150 Chair Program and the European Space Agency PO 5001027396. Data used in this paper were produced as part of the international Multidisciplinary drifting Observatory for the Study of Arctic Climate (MOSAiC): MOSAiC20192020 and AWI_PS122_00. Data are available at the UK
Polar Data Centre. The authors thank the Marine Environmental Observation, Prediction and Response Network (MEOPAR) for a postdoctoral fellowship grant to Vishnu Nandan. The authors also thank the crew of R/V Polarstern and all scientific members of the MOSAiC expedition for their support in field logistics and field data collection.

Financial support. This research has been supported by the Natural Environment Research Council (grant no. NE/S002510/1), the Canada 150 Chair Program (grant no. G00321321) and the European Space Agency (grant no. PO 5001027396).

Review statement. This paper was edited by Chris Derksen and reviewed by Nathan Kurtz and one anonymous referee.

\section{References}

Armitage, T. W. and Ridout, A. L.: Arctic sea ice freeboard from AltiKa and comparison with CryoSat-2 and Operation IceBridge, Geophys. Res. Lett., 42, 6724-6731, 2015.

Barber, D. G. and Nghiem, S. V.: The role of snow on the thermal dependence of microwave backscatter over sea ice, J. Geophys. Res.-Oceans, 104, 25789-5803, 1999.

Barber, D. G., Fung, A. K., Grenfell, T. C., Nghiem, S. V., Onstott, R. G., Perovich, D. K., Lytle, V. I., and Gow, A. J.: The role of snow on microwave emission and scattering over first-year sea ice, IEEE T. Geosci. Remote, 36, 1750-1763, 1998.

Beaven, S. G., Lockhart, G. L., Gogineni, S. P., Hosseinmostafa, A. R., Jezek, K., Gow, A. J., Preovich, D. K., Fung, A. K., and Tjuatja, S.: Laboratory measurements of radar backscatter from bare and snow-covered saline ice sheets, Int. J. Remote Sens., 16, 851-876, 1995.

Bluhm, B. A., Swadling, K. M., and Gradinger, R.: Sea ice as a habitat for macrograzers, Sea Ice, 3, 394-414, 2017.

Cavalieri, D. J., Parkinson, C. L., Gloersen, P., Comiso, J. C., and Zwally, H. J.: Deriving long-term time series of sea ice cover from satellite passive-microwave multisensor data sets, J. Geophys. Res.-Oceans, 104, 15803-15814, 1999.

Drinkwater, M. R.: LIMEX'87 ice surface characteristics: Implications for C-band SAR backscatter signatures, IEEE T. Geosci. Remote, 27, 501-513, 1989.

Drinkwater, M. R.: Airborne And Satellite SAR Investigations Of Sea-Ice Surface Characteristics, in: Oceanographic Applications of Remote Sensing, edited by: Ikeda, M. and Dobson, F., CRC Press, 345-364, 1995.

Drinkwater, M. R., Hosseinmostafa, R., and Gogineni, P.: C-band backscatter measurements of winter sea-ice in the Weddell Sea, Antarctica, Int. J. Remote Sens., 16, 3365-3389, 1995.

Fetterer, F. M., Drinkwater, M. R., Jezek, K. C., Laxon, S. W. C., Onstott, R. G., and Ulander, L. M. H.: Sea Ice Altimetry, in: Microwave Remote Sensing of Sea Ice, edited by: Carsey, F. D., Geophysical Monograph Series, https://doi.org/10.1029/GM068, 1992.

Filhol, S. and Sturm, M.: Snow bedforms: A review, new data, and a formation model, J. Geophys. Res.-Earth, 120, 1645-1669, 2015. 
Geldsetzer, T., Mead, J. B., Yackel, J. J., Scharien, R. K., and Howell, S. E.: Surface-based polarimetric C-band scatterometer for field measurements of sea ice, IEEE T. Geosci. Remote, 45, 3405-3416, 2007.

Giles, K. A., Laxon, S. W., Wingham, D. J., Wallis, D. W., Krabill, W. B., Leuschen, C. J., McAdoo, D., Manizade, S. S., and Raney, R. K.: Combined airborne laser and radar altimeter measurements over the Fram Strait in May 2002, Remote Sens. Environ., 111, 182-194, 2007.

Gill, J. P., Yackel, J. J., Geldsetzer, T., and Fuller, M. C.: Sensitivity of C-band synthetic aperture radar polarimetric parameters to snow thickness over landfast smooth first-year sea ice, Remote Sens. Environ., 166, 34-49, 2015.

Graham, R. M., Cohen, L., Petty, A. A., Boisvert, L. N., Rinke, A., Hudson, S. R., Nicolaus, M., and Granskog, M. A.: Increasing frequency and duration of Arctic winter warming events, Geophys. Res. Lett., 44, 6974-6983, 2017.

Guerreiro, K., Fleury, S., Zakharova, E., Rémy, F., and Kouraev, A.: Potential for estimation of snow depth on Arctic sea ice from CryoSat-2 and SARAL/AltiKa missions, Remote Sens. Environ., 186, 339-349, 2016.

Hallikainen, M. T.: Dieletric properties of $\mathrm{NaCl}$ ice at $16 \mathrm{GHz}, \mathrm{Re}-$ port S-107, Helsinki University of Technology, Radio Laboratory, 37 pp., 1977.

Hendricks, S.: FloeNavi Toolbox, GitHub repository, available at: https://gitlab.awi.de/floenavi-crs/floenavi, last access: October 2020.

Hendricks, S., Ricker, R., and Helm, V.: User guide-AWI CryoSat-2 sea ice thickness data product (v1. 2), AWI User Guide Document, 2016.

Kern, M., Cullen, R., Berruti, B., Bouffard, J., Casal, T., Drinkwater, M. R., Gabriele, A., Lecuyot, A., Ludwig, M., Midthassel, R., Navas Traver, I., Parrinello, T., Ressler, G., Andersson, E., Martin-Puig, C., Andersen, O., Bartsch, A., Farrell, S., Fleury, S., Gascoin, S., Guillot, A., Humbert, A., Rinne, E., Shepherd, A., van den Broeke, M. R., and Yackel, J.: The Copernicus Polar Ice and Snow Topography Altimeter (CRISTAL) highpriority candidate mission, The Cryosphere, 14, 2235-2251, https://doi.org/10.5194/tc-14-2235-2020, 2020.

King, J. M., Kelly, R., Kasurak, A., Duguay, C., Gunn, G., and Mead, J. B.: UW-Scat: A ground-based dual-frequency scatterometer for observation of snow properties, IEEE Geosci. Remote S., 10, 528-532, 2012.

Komarov, A. S., Isleifson, D., Barber, D. G., and Shafai, L.: Modeling and measurement of C-band radar backscatter from snowcovered first-year sea ice, IEEE Geosci. Remote Sens. Lett., 53, 4063-4078, 2015.

Krumpen, T., Birrien, F., Kauker, F., Rackow, T., von Albedyll, L., Angelopoulos, M., Belter, H. J., Bessonov, V., Damm, E., Dethloff, K., Haapala, J., Haas, C., Harris, C., Hendricks, S., Hoelemann, J., Hoppmann, M., Kaleschke, L., Karcher, M., Kolabutin, N., Lei, R., Lenz, J., Morgenstern, A., Nicolaus, M., Nixdorf, U., Petrovsky, T., Rabe, B., Rabenstein, L., Rex, M., Ricker, R., Rohde, J., Shimanchuk, E., Singha, S., Smolyanitsky, V., Sokolov, V., Stanton, T., Timofeeva, A., Tsamados, M., and Watkins, D.: The MOSAiC ice floe: sediment-laden survivor from the Siberian shelf, The Cryosphere, 14, 2173-2187, https://doi.org/10.5194/tc-14-2173-2020, 2020.
Kurtz, N. T., Markus, T., Cavalieri, D. J., Sparling, L. C., Krabill, W. B., Gasiewski, A. J., and Sonntag, J. G.: Estimation of sea ice thickness distributions through the combination of snow depth and satellite laser altimetry data, J. Geophys. Res.-Oceans, 114, C10007, https://doi.org/10.1029/2009JC005292, 2009.

Kurtz, N. T. and Farrell, S. L.: Large-scale surveys of snow depth on Arctic sea ice from Operation IceBridge, Geophys. Res. Lett., 38, L20505, https://doi.org/10.1029/2011GL049216, 2011.

Kurtz, N. and Harbeck, J.: CryoSat-2 Level 4 Sea Ice Elevation, Freeboard, and Thickness, NASA National Snow and Ice Data Center Distributed Active Archive Center, Boulder, Colorado USA, 2017.

Kwok, R. and Markus, T.: Potential basin-scale estimates of Arctic snow depth with sea ice freeboards from CryoSat-2 and ICESat2: An exploratory analysis, Adv. Space Res., 62, 1243-1250, 2018.

Kwok, R., Kacimi, S., Webster, M. A., Kurtz, N. T., and Petty, A. A.: Arctic snow depth and sea ice thickness from ICESat-2 and CryoSat-2 freeboards: A first examination, J. Geophys. Res.-Oceans, 125, e2019JC016008, https://doi.org/10.1029/2019JC016008, 2020.

Landy, J. C., Tsamados, M., and Scharien, R. K.: A facet-based numerical model for simulating SAR altimeter echoes from heterogeneous sea ice surfaces, IEEE T. Geosci. Remote, 57, 41644180, 2019.

Lawrence, I. R., Tsamados, M. C., Stroeve, J. C., Armitage, T. W. K., and Ridout, A. L.: Estimating snow depth over Arctic sea ice from calibrated dual-frequency radar freeboards, The Cryosphere, 12, 3551-3564, https://doi.org/10.5194/tc-12-35512018, 2018.

Laxon, S., Peacock, N., and Smith, D.: High interannual variability of sea ice thickness in the Arctic region, Nature, 425, 947-950, 2003.

Laxon, S. W., Giles, K. A., Ridout, A. L., Wingham, D. J., Willatt, R., Cullen, R., Kwok, R., Schweiger, A., Zhang, J., Haas, C., Hendricks, S., Krishfield, R., Kurtz, N., Farrell, S., and Davidson, M.: CryoSat-2 estimates of Arctic sea ice thickness and volume, Geophys. Res. Lett., 40, 732-737, https://doi.org/10.1002/grl.50193, 2013.

Lee, J. S., Jurkevich, L., Dewaele, P., Wambacq, P., and Oosterlinck, A.: Speckle filtering of synthetic aperture radar images: A review, Remote Sens. Rev., 8, 313-340, 1994.

Livingstone, C. E., Onstott, R. G., Arsenault, L. D., Gray, A. L., and Singh, K. P.: Microwave sea-ice signatures near the onset of melt, IEEE T. Geosci. Remote, 2, 174-187, 1987.

Lytle, V. I., Jezek, K. C., Hosseinmostafa, A. R., and Gogineni, S. P.: Laboratory backscatter measurements over urea ice with a snow cover at Ku band, IEEE T. Geosci. Remote, 31, 10091016, 1993.

Markus, T., Cavalieri, D., and Ivanoff, A.: Algorithm Theoretical Basis Document for the AMSR-E Sea Ice Algorithm, Revised December 2011, Landover, MD, Goddard Space Flight Center, 2011.

Maslanik, J., Stroeve, J., Fowler, C., and Emery, W.: Distribution and trends in Arctic sea ice age through spring 2011, Geophys. Res. Lett., 38, L13502, https://doi.org/10.1029/2011GL047735, 2011.

Maslanik, J. A., Fowler, C., Stroeve, J., Drobot, S., Zwally, J., Yi, D., and Emery, W.: A younger, thinner Arctic ice cover: In- 
creased potential for rapid, extensive sea-ice loss, Geophys. Res. Lett., 34, L24501, https://doi.org/10.1029/2007GL032043, 2007.

Matzl, M. and Schneebeli, M.: Measuring specific surface area of snow by near-infrared photography, J. Glaciol., 52, 558-564, 2006.

Moon, W., Nandan, V., Scharien, R. K., Wilkinson, J., Yackel, J. J., Barrett, A., Lawrence, I., Segal, R. A., Stroeve, J., Mahmud, M., Duke, P. J., and Else, B.: Physical length scales of wind-blown snow redistribution and accumulation on relatively smooth Arctic first-year sea ice, Environ. Res. Lett., 14, 104003, https://doi.org/10.1088/1748-9326/ab3b8d, 2019.

Mundy, C. J., Gosselin, M., Gratton, Y., Brown, K., Galindo, V., Campbell, K., Levasseur, M., Barber, D., Papakyriakou, T., and Bélanger, S.: Role of environmental factors on phytoplankton bloom initiation under landfast sea ice in Resolute Passage, Canada, Mar. Ecol. Progr. Ser., 497, 39-49, 2014.

Nandan, V., Geldsetzer, T., Islam, T., Yackel, J. J., Gill, J. P., Fuller, M. C., Gunn, G., and Duguay, C.: Ku-, X-and C-band measured and modeled microwave backscatter from a highly saline snow cover on first-year sea ice, Remote Sens. Environ., 187, 62-75, https://doi.org/10.1016/j.rse.2016.10.004, 2016.

Nandan, V., Scharien, R., Geldsetzer, T., Mahmud, M., Yackel, J. J., Islam, T., Gill, J. P. S., Fuller, M. C., Gunn, G., and Duguay, C.: Geophysical and atmospheric controls on $\mathrm{Ku}-, \mathrm{X}$-and C-band backscatter evolution from a saline snow cover on first-year sea ice from late-winter to pre-early mel, Remote Sens. Environ., 198, 425-441, https://doi.org/10.1016/j.rse.2017.06.029, 2017a.

Nandan, V., Geldsetzer, T., Yackel, J., Mahmud, M., Scharien, R., Howell, S., King, J., Ricker, R., and Else, B.: Effect of snow salinity on CryoSat-2 Arctic first-year sea ice freeboard measurements, Geophys. Res. Lett., 44, 10419-10426, https://doi.org/10.1002/2017GL074506, 2017b.

Nandan, V., Geldsetzer, T., Mahmud, M., Yackel, J., and Ramjan, $\mathrm{S}$.: $\mathrm{Ku}-, \mathrm{X}$-and $\mathrm{C}$-Band microwave backscatter indices from saline snow covers on Arctic first-year sea ice, Remote Sens., 9, 757, https://doi.org/10.3390/rs9070757, 2017c.

Nandan, V., Scharien, R. K., Geldsetzer, T., Kwok, R., Yackel, J. J., Mahmud, M. S., and Stroeve, J.: Snow Property Controls on Modeled Ku-Band Altimeter Estimates of First Year Sea Ice Thickness: Case studies from the Canadian and Norwegian Arctic, IEEE J. Sel. Top. Appl., 13, 1082-1096, 2020.

Nghiem, S. V., Borgeaud, M., Kong, J. A., and Shin, R. T.: Polarimetric remote sensing of geophysical media with layer random medium model, Prog. Electromagn. Res., 3, 1-73, 1990.

Nghiem, S. V., Kwok, R., Yueh, S. H., and Drinkwater, M. R.: Polarimetric signatures of sea ice: 1 . Theoretical model, J. Geophys. Res.-Oceans, 100, 13665-13679, 1995.

Onstott, R. G., Moore, R. K., and Weeks, W. F.: Surface-based scatterometer results of Arctic sea ice, IEEE T. Geosc. Elect., 17, 78-85, 1979.

Parkinson, C. L. and Cavalieri, D. J.: A 21-year record of Arctic seaice extents and their regional, seasonal and monthly variability and trends, Ann. Glaciol., 34, 441-446, 2002.

Proksch, M., Löwe, H., and Schneebeli, M.: Density, specific surface area, and correlation length of snow measured by highresolution penetrometry, J. Geophys. Res.-Earth, 120, 346-362, 2015.

Ricker, R., Hendricks, S., Helm, V., Skourup, H., and Davidson, M.: Sensitivity of CryoSat-2 Arctic sea-ice freeboard and thick- ness on radar-waveform interpretation, The Cryosphere, $8,1607-$ 1622, https://doi.org/10.5194/tc-8-1607-2014, 2014.

Rostosky, P., Spreen, G., Farrell, S. L., Frost, T., Heygster, G., and Melsheimer, C.: Snow depth retrieval on Arctic sea ice from passive microwave radiometers-Improvements and extensions to multiyear ice using lower frequencies, J. Geophys. Res.-Oceans, 123, 7120-7138, 2018.

Sarabandi, K., Ulaby, F. T., and Tassoudji, M. A.: Calibration of polarimetric radar systems with good polarization isolation, IEEE T. Geosci. Remote, 28, 70-75, 1990.

Shalina, E. V. and Sandven, S.: Snow depth on Arctic sea ice from historical in situ data, The Cryosphere, 12, 1867-1886, https://doi.org/10.5194/tc-12-1867-2018, 2018.

Stroeve, J. and Notz, D.: Changing state of Arctic sea ice across all seasons, Environ. Res. Lett., 13, 103001, https://doi.org/10.1088/1748-9326/aade56, 2018.

Stroeve, J., Liston, M. C., Buzzard, S., Zhou, L., Mallett, R., Barrett, A., Tschudi, M. Tsamados, M., Itkin, P., and Stewart, J. S.: A Lagrangian snow-evolution system for sea ice applications (SnowModel-LG): Part II - Analyses, J. Geophys. Res.-Oceans, https://doi.org/10.1029/2019JC015900, 2020a.

Stroeve, J., Nandan, V., Tonboe, R., Hendricks, S., Ricker, R., and Spreen, G.: Ku- and Ka-band polarimetric radar backscatter of Arctic sea ice between October 2019 and September 2020 (Version 1.0) [Data set], UK Polar Data Centre, Natural Environment Research Council, UK Research \& Innovation, https://doi.org/10.5285/5FB5FBDE-7797-44FAAFA6-4553B122FDEF, 2020b.

Stroeve, J. C., Serreze, M. C., Holland, M. M., Kay, J. E., Malanik, J., Barrett, A. P.: The Arctic's rapidly shrinking sea ice cover: a research synthesis, Climatic change, 110, 1005-1027, 2012.

Sturm, M. and Holmgren, J.: An automatic snow depth probe for field validation campaigns, Water Res. Res., 54, 9695-9701, 2018.

Tilling, R. L., Ridout, A., and Shepherd, A.: Estimating Arctic sea ice thickness and volume using CryoSat-2 radar altimeter data, Adv. Space Res., 62, 1203-1225, 2018.

Tonboe, R., Andersen, S., and Pedersen, L. T.: Simulation of the Ku-band radar altimeter sea ice effective scattering surface, IEEE Geosci. Remote S., 3, 237-240, 2006.

Tonboe, R. T.: Improve the understanding of the influence of snow properties on radar return (The ESA sea ice climate change initiative phase 2 WP2220), Radar backscatter modelling for sea ice radar altimetry, DMI Report, available at: https://www.dmi.dk/fileadmin/user_upload/Rapporter/ TR/2017/DMIRep17-17_rtt.pdf (last access: August 2020), 2017.

Tonboe, R. T., Toudal Pedersen, L., and Haas, C.: Simulation of the CryoSat-2 satellite radar altimeter sea ice thickness retrieval uncertainty, Can. J. Remote Sens., 36, 55-67, https://doi.org/10.5589/m10-027, 2010.

Ulaby, F. T., Moore, R. K. and Fung, A. K.: Microwave remote sensing: Active and passive, in: Radar Remote Sensing and Surface Scattering and Emission Theory, Artech House Publishers, Norwood, USA, 962-966, 1986.

Warren, S. G., Rigor, I. G., Untersteiner, N., Radionov, V. F., Bryazgin, N. N., Aleksandrov, Y. I., and Colony, R.: Snow depth on Arctic sea ice. J. Climate, 12, 1814-1829, 1999. 
Webster, M. A., Rigor, I. G., Nghiem, S. V., Kurtz, N. T., Farrell, S. L., Perovich, D. K., and Sturm, M.: Interdecadal changes in snow depth on Arctic sea ice, J. Geophys. Res.-Oceans, 119, 53955406, 2014.

Willatt, R., Laxon, S., Giles, K., Cullen, R., Haas, C., and Helm, $\mathrm{V} . \mathrm{Ku}$-band radar penetration into snow cover on Arctic sea ice using airborne data. Ann. Glaciol., 52, 197-205, 2011.

Winebrenner, D. P., Long, D. G., and Holt, B.: Mapping the progression of melt onset and freeze-up on Arctic sea ice using SAR and scatterometry, in Analysis of SAR Data of the Polar Oceans, Springer, Berlin, Heidelberg, 129-144, 1998.
Wingham, D. J., Francis, C. R., Baker, S., Bouzinac, C., Brockley, D., Cullen, R., Chateau-Thierry, P., Laxon, S. W., Mallow, U., Mavrocordatos, C., Phalippou, L., Ratier, G., Rey, L., Rostan, F., Viau, P., and Wallis, D.: CryoSat: A mission to determine the fluctuations in Earth's land and marine ice fields, Adv. Space Res., 37, 841-871, 2006.

Yackel, J. J. and Barber, D. G.: Observations of snow water equivalent change on landfast first-year sea ice in winter using synthetic aperture radar data, IEEE T. Geosci. Remote, 45, 1005-1015, 2007. 